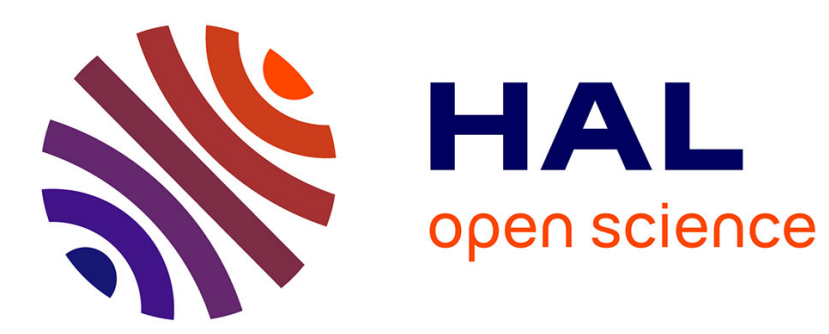

\title{
Effects of infant formula composition on long-term metabolic health
}

\author{
Marion Lemaire, Isabelle Le Huërou-Luron, Sophie Blat
}

\section{To cite this version:}

Marion Lemaire, Isabelle Le Huërou-Luron, Sophie Blat. Effects of infant formula composition on long-term metabolic health. Journal of Developmental Origins of Health and Disease, 2018, 9 (6), pp.573-589. 10.1017/S2040174417000964 . hal-01723931

\section{HAL Id: hal-01723931 \\ https://hal.science/hal-01723931}

Submitted on 21 Jun 2018

HAL is a multi-disciplinary open access archive for the deposit and dissemination of scientific research documents, whether they are published or not. The documents may come from teaching and research institutions in France or abroad, or from public or private research centers.
L'archive ouverte pluridisciplinaire HAL, est destinée au dépôt et à la diffusion de documents scientifiques de niveau recherche, publiés ou non, émanant des établissements d'enseignement et de recherche français ou étrangers, des laboratoires publics ou privés. 


\section{Effects of infant formula composition on long-term metabolic health}

M. Lemaire ${ }^{1-2}$, I. Le Huërou-Luron ${ }^{1}$, S. Blat ${ }^{1}$

${ }^{1}$ INRA, INSERM, Univ Rennes, Nutrition Metabolisms and Cancer (NuMeCan), Rennes, France

${ }^{2}$ Lactalis R\&D, Retiers, France

Short Title: Infant formula and long-term metabolic health 


\begin{abstract}
Early nutrition may have long-lasting metabolic impacts in adulthood. Even though breast milk is the gold standard, most infants are at least partly formula-fed. Despite obvious improvements, infant formulas remain perfectible to reduce the gap between breastfed and formula-fed infants. Improvements such as reducing the protein content, modulating the lipid matrix, and adding prebiotics, probiotics and synbiotics, are discussed regarding metabolic health. Numerous questions remain to be answered on how impacting the infant formula composition may modulate the host metabolism and exert long-term benefits. Interactions between early nutrition (composition of human milk and infant formula) and the gut microbiota profile, as well as mechanisms connecting gut microbiota to metabolic health, are highlighted. Gut microbiota stands as a key actor in the nutritional programming but additional well-designed longitudinal human studies are needed.
\end{abstract}

Key words: early nutrition, gut microbiota, metabolism, neonatal feeding, nutritional programming 
Over the last decades, metabolic diseases such as insulin resistance (IR), type-2 diabetes (TD2) and obesity have dramatically increased in both children and adults. Thus, worldwide prevalence of obesity has more than doubled between 1980 and 2014. ${ }^{1}$ The pandemic of obesity and associated comorbidities may find part of its origin in the early postnatal life. Indeed, according to the developmental origins of health and disease (DOHaD), the foetal period and the first few months of postnatal life are a critical window for determining the flexibility of the system to cope with challenges in later life., ${ }^{2,3,4}$ Quality and quantity of early nutrition plays a crucial role since it can have a great influence on developing infants' metabolism, impacting weight gain, adiposity and energy metabolism on the short and longterm through physiological and behavioural pathways. ${ }^{5}$ Breast milk is recognized as the ideal nutrition for the full-term newborn. An exclusive breastfeeding for the first six months of life is therefore recommended by the World Health Organization. However, despite these recommendations, breastfeeding rates remain low. In 2013 in the United States, $81.1 \%$ of infants were breastfed at birth but only $22.3 \%$ were exclusively breastfed at the age of 6 months. ${ }^{6}$ The same occurs in Europe, despite large disparities between countries, with breastfeeding rates beyond 4-6 months well below optimum levels. ${ }^{7}$ When breastfeeding is not possible or wanted, the only alternatives are infant formulas (IF). Despite obvious improvements over the past 50 years, IF remain perfectible to better approach the physiologic effects of breast milk. The objective of this review is to summarize differences between breastfed and formula-fed infants on long-term metabolic health, focusing on vaginal, termborn, healthy infants. It will then highlight the modifications that have already been made and that can further be made to IF in order to better mimic the physiological effects of breast milk on both the short- and long-terms. Finally, it will attempt to approach the mechanisms, focusing on the ones involving gut microbiota, as it is known to be impacted by early nutrition and has a key role in regulating metabolism. For space reasons, the effects of early-life 3 
nutritional exposures on infections and immune diseases such as allergy and the interactions between gut microbiota and the immune system, recently published elsewhere, ${ }^{8,9}$ will not be addressed in this review. Similarly, behavioural mechanisms, such as programming of food preferences and eating behaviour, will not be discussed, even though the early postnatal period is known to be essential for the establishment of odors and taste preferences and their maintenance in later life. ${ }^{10,11,12,13}$

\section{Metabolic health benefits of breastfeeding compared to formula-feeding}

Early nutrition is known to play a fundamental role in regulating body development and maturation of tissue functions with short- and long-term organ- specific and time of intervention-specific responses. ${ }^{14,15}$ The first months of life are thus a critical time for preventing metabolic and cardiovascular disorders and obesity in later life. Infant growth trajectory and weight gain during the first year of life are one of the best predictors of obesity in later life, with an increase of $1 \mathrm{SD}$ in weight z-score being associated with a 2-fold higher obesity risk in childhood and a $23 \%$ higher obesity risk in adulthood. ${ }^{16,17}$ More precisely, weight gain during the first 6 months of life is a better indicator of body composition in adolescence than weight gain from 6 months to 2 years of age. ${ }^{18,19}$ The early pattern of body fatness is also indicative of later obesity: obese adults have often had an earlier adiposity rebound (at 3 years of age) than non-obese adults (at 6 years of age).$^{20}$ Indeed, the early period of life is a sensitive period during which adipose tissue expands dramatically since the proliferative capacity of adipose precursor cells from sub-cutaneous adipose tissue is at its highest. $^{21}$ Therefore, numerous studies aiming at understanding the relationship between nutrition, growth in the first years of life and later risks for cardio-metabolic disorders focused on the comparison between breastfed and formula-fed infants. 


\section{Growth and body composition}

Breastfed infants have a slower growth trajectory during the first months of life compared to formula-fed infants. ${ }^{22,23,24,25}$ The advanced growth tempo, higher weight gain and earlier adiposity rebound of formula-fed children could lead to a higher obesity risk. ${ }^{20,23,26,27,28}$ Indeed, formula-fed neonates would have a $22 \%$ higher risk of obesity in infancy compared to breastfed infants. ${ }^{29}$ Although the magnitude of breastfeeding protection may decrease over time, a $13 \%$ reduction in overweight and obesity has still been observed among adults. ${ }^{30}$ An exclusive breastfeeding would be more efficient to prevent childhood obesity than mixedfeeding (breast milk and IF), itself more efficient than exclusive formula-feeding. ${ }^{31}$ Introducing an IF before 3 months may indeed increase odds of rapid growth in the first 6 years and is associated with higher mean body mass index (BMI) 20 years later. ${ }^{27}$ However, the results of other clinical studies do not allow a clear conclusion on the relationship between an exclusive breastfeeding and a lower risk of childhood obesity. ${ }^{32,33,34,35}$ The influence of non-investigated confounding factors such as the composition of human milk and its oligosaccharide content may explain the discrepancies between studies. ${ }^{36}$ As Beyerlein and von Kries already stated, it appears doubtful whether there will ever be a study conducted that will have the appropriate methodology and the statistical power to conclude for or against a potential protective effect of breastfeeding against childhood overweight. ${ }^{37}$

\section{Metabolism / Metabolic disorders}

\section{Insulin resistance and type-2 diabetes}

Milk composition has a strong influence on metabolic programming. Besides, weight gain between birth and 3 years of age predicted insulin sensitivity, BMI and waist circumference at the age 8 years. ${ }^{38}$ Formula-fed infants are at higher risk for IR and T2D in later life than the breastfed ones. ${ }^{30,39,40}$ Much higher urinary C-peptide concentrations (used as a measure of 5 
insulin secretion) were found in formula-fed infants compared to breastfed infants ${ }^{41}$ as well as higher pre- and postprandial blood glucose levels. ${ }^{39}$ If higher glycaemia of formula-fed compared to breastfed infants no more persist in later life, differences in insulinaemia do continue. Breastfed infants have 3\% lower insulin levels in later life (childhood and adulthood) compared to the formula-fed ones. ${ }^{39}$ At 8 years of age, overweight and obese infants formula-fed for 4 months or longer were more insulin-resistant than the ones that were breastfed, and they compensated their lesser sensitivity by a higher insulin secretion. ${ }^{42}$ These greater insulin levels in formula-fed infants may explain their greater deposition of subcutaneous adipose tissue ${ }^{43}$ and may be due to a faster increase in serum branched-chain amino acids ${ }^{44}$ as demonstrated in both animal ${ }^{45}$ and human ${ }^{46,47,48,49,50}$ studies.

\section{Cardiovascular risks factors}

Early nutrition may also have an impact on cardiometabolic risk factors (dyslipidaemia and hypertension) and atherosclerosis in later life. Formula-fed infants could be at higher risk of atherosclerosis as a negative correlation has been found between inflammatory markers serum levels (serum monocyte chemoattractant protein-1 level and uric acid) and duration of breastfeeding. ${ }^{51}$ Besides, observational studies suggested that formula-feeding could be associated with higher blood pressure levels in childhood compared to breastfeeding. ${ }^{52,53} \mathrm{~A}$ prospective study on Mexican children concluded that an exclusive and prolonged breastfeeding had a beneficial effect on later cardiometabolic health through lower total cholesterol, low-density lipoprotein cholesterol and triglycerides levels at the age of $4 .{ }^{54}$ Some studies demonstrated that these lower levels persisted even later in adulthood (from 17 to 64 years). ${ }^{55}$ Yet, earlier at 4 and 8 weeks of life, formula-fed infants have lower serum cholesterol, triglyceride and transaminase level (ALAT, ASAT, $\gamma \mathrm{GT}$ ) compared to breastfed infants. ${ }^{56}$ The higher levels of cholesterol in breastfed infants before 1 year of age can be 
explained by the higher level of cholesterol in breast milk compared to IF made with vegetable oils. ${ }^{55}$ The twist in cholesterol levels between formula-fed and breastfed infants may be due to a nutritional programming of cholesterol synthesis by early postnatal diet. ${ }^{57} \mathrm{In}$ a pig model, the lower serum cholesterol concentration in formula-fed piglets compared to the breastfed ones was associated with an increase in mRNA encoding cholesterol 7 alphahydroxylase. ${ }^{58}$ Despite the above studies, the long-term benefits of breastfeeding on preventing cardiovascular diseases remain controversial ${ }^{30,59,60,61}$ and further studies are required. Clearer results are mandatory to decipher whether reduced cholesterol level in early life has long-term deleterious consequences or not. A modest decrease in cholesterol level in adulthood could lead to a $5 \%$ reduction in coronary heart disease incidence. ${ }^{57}$

\section{Improving infant formulas to approach the physiologic effects of breast}

\section{milk}

Breast milk remains the gold standard and the objective is therefore to improve the composition of IF to better approach its physiologic effects. Breast milk has a unique composition that leads to specific metabolic and physiological responses. ${ }^{62}$ Several factors have been suggested to explain the association between formula-feeding, growth, body composition and later risk of obesity and metabolic diseases. Differences in qualitative and quantitative intake in nutrients, hormones and milk bacteria may be involved. Since IF composition has greatly evolved and been improved over the last decades, cautiousness is needed when interpreting results from older cohorts. ${ }^{63}$ 


\section{Macronutrients}

\section{Proteins}

Cow's milk proteins are the unique source of proteins in most IF but have a lower quality compared to breast milk, partly because of differences in their amino acid contents. Over the last decades, the amount of protein per energy content has generally been higher in IF than in human milk $(0.9 \mathrm{~g} / 100 \mathrm{~mL} \text { in mature milk, } 1.29-1.38 \mathrm{~g} / 100 \mathrm{kcal})^{64}$ to meet infant's protein and amino acid requirements. ${ }^{65}$ Old studies from the 1990s reported that formula-fed infants aged 3-12 months had 10-18\% higher energy intakes and 55-80\% higher protein supply per $\mathrm{kg}$ of body weight than breastfed infants. ${ }^{66,67} \mathrm{~A}$ high protein intake in early infancy has been associated with an increased growth and higher later adiposity. ${ }^{68,69,70,71} \mathrm{~A}$ high protein intake during the first year of life thus affected fat distribution in healthy children with an enhanced pre-peritoneal fat (a marker of visceral fat) but not subcutaneous fat tissue accumulation at the age 5 years $^{70}$ and higher fat mass but not fat free mass at the age 6 years ${ }^{71}$. According to the early protein hypothesis, the higher protein content in IF could lead to increased circulating concentrations of insulin-releasing amino acids, stimulating the release of insulin and insulinlike growth factor I (IGF-1) and resulting in an accelerated growth, a faster weight gain and a greater adiposity. ${ }^{72}$ Formula-fed infants have higher levels of IGF-1 than breastfed infants at several ages and IGF-1 levels at 7-8 years of age was associated with the history of breastfeeding. ${ }^{73,74,75}$ The early protein hypothesis was supported by a systematic literature review that assessed that a higher protein intake in infancy and early childhood was convincingly associated with increased growth and higher BMI in childhood, the first 2 years of life being likely most sensitive to high protein intake. ${ }^{76}$ However, inconsistent evidence is available on the association beyond infancy and on later childhood overweight or obesity. ${ }^{77}$

An improvement of IF has consisted in decreasing their protein content without altering the plasma amino acid profile. Two approaches has been considered: an increase in the proportion 8 
of $\alpha$-lactalbumin ${ }^{78,79}$ and, if necessary, the addition of free limiting amino acids ${ }^{80}$ However, the addition of free amino acids in IF may have long-term metabolic outcomes since they will be absorbed and oxidized more rapidly than protein-bound amino acids. ${ }^{81}$

Infants fed a low-protein IF were lighter at the age 2 but had similar height than infants fed a high-protein $\mathrm{IF}^{82}$ and their weight and $\mathrm{BMI}$ as well as their metabolism were closer to the ones of BF infants. ${ }^{83}$ At the age 6 , their obesity risk was lower ${ }^{84}$ and at the age 14-16 years, it is expected to be $13 \%$ lower. ${ }^{83}$ Other factors than IGF-1 may also impact growth velocity since decreasing the IF protein content did not impact plasma IGF-1, insulin and C-peptide concentrations during the first year of life and body composition during the first 60 months of life but affected length and head circumference growth in a French randomised controlled trial $^{85}$ Decreasing the protein content in IF may also decrease the level of metabolic stress ${ }^{45}$ by decreasing plasma levels of insulinogenic amino acids close to those induced by breast milk as well as urinary C-peptide level. ${ }^{41}$

An ideal protein content of $1.8 \mathrm{~g} / 100 \mathrm{kcal}$ was therefore established for standard milk protein-based $\mathrm{IF}^{86}$ and protein content in IF is now relatively close to the one found in breast milk. ${ }^{87}$ Human milk also contains bioactive proteins such as lactoferrin (present at higher concentration in human milk compared to IF), ${ }^{88}$ hormones and cytokines that may affect growth, body composition and metabolism in later life and explain differences observed between breastfed and formula-fed infants..$^{89,90,91,92}$ The supplementation of IF with bovine lactoferrin may help narrow the gap between breastfed and formula-fed infants. ${ }^{93}$ However, long-term and mechanistic studies are still missing.

\section{Fat quality and structure}

If in the early $20^{\text {th }}$ century the fat matrix of IF was made of cow's milk fat and butterfat, today the fat matrix of most IF is exclusively made of a blend of vegetable oils. The use of 9 
vegetable oils enabled to better mimic the human milk mono- and polyunsaturated fatty acid profiles $^{21}$ but induced major differences in the fat globule and triglycerides structure. Regarding fatty acid profile, IF usually contain more long-chain polyunsaturated fatty acids (LC-PUFAs) of the $\omega 3$ and $\omega 6$ families due to their supplementation. If $\omega 3$ LC-PUFAs have been associated with improved insulin sensitivity, reduced body weight gain and adiposity and counteraction of dyslipidaemia in adult human and animal studies, ${ }^{94}$ data on nutritional programming by postnatal $\omega 3$ LC-PUFAs are limited. In a male murine model, postnatal supplementation with $\omega 3$ PUFAs reduced body fat deposition during adulthood and led to less hypertrophic adipocytes and healthier plasma lipid profile and glucose homeostasis. ${ }^{95}$ Similar beneficial effects were observed with a low $\omega 6$ PUFA diet ${ }^{96}$. Both diets (high in $\omega 3$ and low in $\omega 6)$ affected permanently the development of the central regulatory circuits controlling energy balance..$^{97}$ The higher amount of $\omega 6$ fatty acids in IF than in breast milk may promote the adipose tissue development by enhancing the formation of pre-adipocytes ${ }^{21}$ and the arachidonic acid (ARA, $\omega 6$ ) and its metabolites may directly be involved. ${ }^{21,98}$ However, a recent systematic review has concluded on the lack of evidence on consumption of LCPUFA-supplemented IF and later risk of obesity. ${ }^{99}$ Moreover, the supplementation of IF with ARA and docosahexaenoic acid (DHA, $\omega 3$ ) has proven to be efficient to lower blood pressure in children at the age 6 years and potentially their cardiovascular risk in adulthood compared to their counterparts who had received a non-supplemented formula. ${ }^{100}$ A balanced ratio between $\omega 3$ and $\omega 6$ is essential ${ }^{101,102}$ however, the addition of DHA (20-50 mg/100 kcal) but not ARA is now mandatory in IF for full-term healthy neonates, ${ }^{103}$ which raises questions regarding the suitability and safety of these IF. ${ }^{104,105,106}$

Beyond fatty acid composition, the lipid matrix is also of great importance. Indeed, breast milk contains fat globules surrounded by a complex trilayer membrane called milk fat globule membrane (MFGM) rich in phospholipids ( $30 \%$ of total lipid weight, mainly sphingomyelin, 10 
phosphatidylcholine and phosphatidylethanolamine), cholesterol and proteins (lipid:protein weight ratio of 1:1). ${ }^{107}$ Due to homogenization and thermal treatments, the structure of fat in IF is different in size of lipid droplets, interfacial composition and architecture, and fatty acid profile. ${ }^{108,109}$ Besides, IF with a lipid matrix made only with vegetable oils do not contain MFGM. A clinical study displayed no effect of MFGM supplementation in IF on growth and LDL:HDL ratio, but a higher plasma cholesterol trajectory from 2 to 6 months, that did not persist at 12 months of age. ${ }^{110}$ In another study, providing an IF supplemented with cream and a bovine MFGM concentrate for 2 months normalized cholesterol and LDL concentrations to levels of breastfed infant. ${ }^{111}$ Animal studies can provide a better understanding of the importance of the structure and composition of fat matrix. In a murine model, male pups given an experimental formula with large lipid droplets coated with MFGM mimicking milk fat globules from 16 until 42 days of age displayed lower fat accumulation (by 30\%) and lower fasting plasma leptin, resistin, glucose and lipid concentrations as adults compared to mice given a standard vegetable-fat-based formula. ${ }^{112}$ Their adipocyte size was lower yet not their number and some key regulators of metabolic activity, such as PPAR $\gamma$, were less expressed in their white adipose tissue reducing their susceptibility to obesity in later life. ${ }^{113}$ Baars et al. ${ }^{114}$ recently demonstrated that both the large droplets and the MFGM coating were mandatory to induce such effects. A suggested mechanism would be a reduction in lipid storage capacity and a decline in lipogenesis in white adipose tissue. In infants, such an IF containing large, phospholipid-coated lipid droplets was found to support adequate growth in healthy Asian infants during the first 4 months of life compared to a standard IF. ${ }^{115}$

Besides, the supplementation of IF with cholesterol by a direct addition of cholesterol or by replacing a fraction of vegetable oils by dairy lipids may have a beneficial effect on cholesterol level in adulthood. The addition of dairy lipids in IF enabled a normal growth during the 4 months of feeding. ${ }^{116}$ Supplementation in cholesterol $(3.44 \mathrm{mmol} / \mathrm{l}$ vs. 0.85 11 
$\mathrm{mmol} / \mathrm{l}$ in the regular cow's milk protein-based formula) of IF given to full-term healthy neonates did not modify plasma cholesterol concentrations at 4, 11 and 12 months of age. Both cholesterol-supplemented and not-supplemented formula-fed groups differed from the breastfed group at 4 months for plasma total-cholesterol but not at 11 and 12 months. ${ }^{117}$ In another study, differences were observed at 4 months but did not persist at 18 months. ${ }^{118}$ The lack of differences might be explained by the short-term follow-ups or by the bioavailability of the added cholesterol (unesterified in formula $v s$. free and esterified in breast milk). The efficiency of cholesterol absorption may also be decreased by phytosterols present in infant formulas, competing in bile salt/lecithin micelles. ${ }^{119}$ In order to ressemble the animal/plant sterol ratio of human milk, plant sterols should be reduced. ${ }^{120}$ Long-term human and animal studies are still needed to conclude on the outcomes of the addition of cholesterol in infant formulas.

\section{Carbohydrates and oligosaccharides}

\section{Human milk vs. formula-feeding}

Lactose is the main carbohydrate source in both human milk and standard IF and also the most stable of all macronutrients with a concentration of about $67-74.4 \mathrm{~g} / \mathrm{L}(10.3-11.4 \mathrm{~g} / 100$ kcal) in human milk. ${ }^{90,121}$ Animal studies have demonstrated adverse long-term effects of an increased intake of carbohydrate in early life. Indeed, the supply of a high-carbohydrate (polycose) formula to 4-day-old rat pups during the suckling period led to chronic hyperinsulinemia and adult-onset obesity. These effects were mediated by numerous adaptations in 12-day-old rats targeting pancreatic islets, including the autonomic regulation of insulin secretion, the gut (increased GLP-1 levels) and possibly the hypothalamus. The phenotype was also spontaneously transmitted to the progeny. ${ }^{122}$ Yet, carbohydrates levels in IF do fit that of breast milk and such high carbohydrate IF are not available. 
Human milk also contains a high quantity of oligosaccharides (third largest component after lactose and lipids, 5-20 g/L in mature milk) (HMOs), which are unconjugated glycans composed of 5 monosaccharide building blocks (D-glucose, D-galactose, Nacetylglucosamine, L-fucose, and sialic acid derivative $\mathrm{N}$-acetyl-neuraminic acid) associated under more than 200 distinct forms. The total amount and composition of HMOs are highly variable between women, depending on maternal genetic, lactation stages and environmental factors (such as geographic localization, diet and physical activity). ${ }^{123,124,125,126,127}$ Resistant to digestion, HMOs reach intact the distal small intestine and colon where they are fermented by the gut microbiota, sometimes in a strain-specific manner. For instance, $B$. infantis grows well on several HMOs, but most bifidobacterial species only metabolize the lacto-N-tetraose, one of the predominant HMOs. ${ }^{123,124,125,126,128}$ Members of the genus Bacteroides are also known to consume specific HMOs. ${ }^{129}$ Different HMOs may therefore differently shape gut microbiota composition and activity through modulation of human milk microbiota. ${ }^{130}$ For instance, 2'-fucosyllactose (2'FL) has been linked to a greater abundance of gut bifidobacteria and infants whose mother are non-secretor would have a delayed establishment of bifidobacteria-laden microbiota, ${ }^{131}$ with lasting consequences on the gut microbiota at 2 to 3 years of age. ${ }^{132}$ Milk HMOs can be positively or negatively correlated with a number of bacteria in the stool of breastfed infants. ${ }^{133}$ In addition to their action on gut microbiota, HMOs may exert direct effects on intestinal epithelial cells ${ }^{134,135,136}$ or potential systemic effects by reaching the circulation. ${ }^{137,138}$ Therefore, either directly or indirectly, they can impact health on both the short- and long-terms. For instance, milk HMO diversity and evenness at 1 and 6 months of lactation were associated to the suckling infant's weight and body composition (lean and fat mass). These preliminary results need to be corroborated by higher sample sizes and longer follow-up to elucidate the exact contribution of specific HMOs to infant development. ${ }^{139}$ 


\section{Prebiotics in infant formulas}

Until recently, individual HMOs were not available at large-scale and therefore could not be added to IF. Furthermore, the complex mixture of HMOs cannot be reproduced in IF. The addition of prebiotics, substrates "selectively utilized by host microorganisms conferring a health benefit", ${ }^{140}$ has been a first step to approach HMOs benefits in IF. Studied prebiotics in IF have mainly been a 9:1 mixture of short-chain galacto-oligosaccharides (scGOS) and longchain fructo-oligosaccharides (lcFOS), or (used single or combined) GOS, FOS, acidic oligosaccharides, oligofructose, inulin, polydextrose or lactulose, with considerable variations in doses and duration of administration between clinical studies. ${ }^{141}$ If prebiotic supplementation has been associated with a slightly greater weight gain in a systematic review of randomized controlled trials, ${ }^{142}$ small sample sizes and the lack of statistical power and long-term follow-up complicate the interpretation of the effects of prebiotic-supplemented IF. A routine use of prebiotic-supplemented IF is therefore not legally recommended. ${ }^{141}$ Besides, prebiotics commonly added to IF are much simpler structures than HMOs and cannot reproduce all their benefits, most of them being structure-specific. For instance, prebiotics such as FOS and GOS are known to be broadly bifidogenic whereas HMOs are metabolized by a smaller array of bifidobacteria. ${ }^{126}$ Short-chain fatty acids (SCFAs), such as acetate, propionate and butyrate, are a major product of gut microbiota fermentation. They are a source of metabolizable energy and they can be used as signalling molecules and involved in de novo lipid synthesis. ${ }^{143}$ SCFAs may have a beneficial role on weight gain and adiposity in infants. ${ }^{144}$ However, prebiotic supplementation does not seem to affect the biochemical parameters in the blood and urine samples ${ }^{145}$ and different combination of prebiotics have demonstrated similar efficacy on gut microbiota composition ${ }^{146}$ and on growth rate. ${ }^{147}$ Longterm health outcomes of neonatal prebiotic supplementation in IF have not been extensively 
described yet. A small explorative study on a specific population of hepatitis $\mathrm{C}$ virus-infected mothers demonstrated differences in gut microbiota composition at the age of 12 months between infants fed a scGOS/lcFOS-supplemented IF during the first 6 months of life compared with the placebo group. ${ }^{148}$

Other potential prebiotics are oligosaccharides present in the milk of farm animals such as cows and goats. Even if their oligosaccharide concentrations are 100-1000-fold lower than in human milk and less diverse, ${ }^{123}$ they may represent an alternative source of prebiotics. ${ }^{149}$ Individual HMOs like 2'FL and lacto-N-neotetraose (LNnT), which account for $\sim 37 \%$ of total HMOs, are now commercially available and provide more promising opportunities for the development of IF closer to breast milk. ${ }^{150}$ The supplementation with 2 HMOs (2'FL and LNnT) for 6 months did not induce differences in weight, length, BMI or corresponding zscores through 12 months compared to a non-supplemented IF, ${ }^{151}$ but induced a faecal microbiota and metabolic signature closer to that of breastfed infants at 3 months of age. ${ }^{152}$ No significant differences were further observed for weight, length, or head circumference growth during a 4-month study period between infants fed IF containing GOS and supplemented or not with $2^{\prime}$ FL. ${ }^{153}$

If the smallest and most abundant HMOs are now available, the more complex ones are not. Besides, several questions remain regarding which HMO composition should be considered as ideal and therefore which HMOs should be added to IF, their dosage and their short- and long-term health consequences. ${ }^{154}$

\section{Probiotics and synbiotics}

Formerly considered to be sterile, human milk has recently been recognized as a continuous source of viable commensal and potentially probiotic bacteria such as Staphylococcus, Streptococcus, Bifidobacterium and Lactobacillus. ${ }^{125}$ If over 200 different 
bacterial species (from 50 different genera) have previously been identified in human milk, ${ }^{155}$ recent studies revealed a larger microbial diversity with over 200 different genera and 700 species. ${ }^{156,157}$ The origin of bacteria present in breast milk is not fully elucidated but the current hypothesis is that bacteria from the maternal gut may be trapped by dendritic cells and spread to the mammary gland via the lymphatic and blood circulation, ${ }^{125}$ although an additional retro-contamination of mammary gland by infant oral microbiota cannot be ruled out. Core milk microbiomes composed of genera present in most human milk samples have been identified with 9 genera accounting for half of the microbial community ${ }^{155}$ or 12 genera accounting for more than $81 \%$ and $73 \%$ of the taxa identified before week 6 and at week 12 of lactation, respectively, ${ }^{157}$ with 3 genera shared between these two studies. Human milk microbiome is affected by external factors such as maternal nutrition, gestational age, health status and delivery mode, and also varies across lactation. ${ }^{125,158}$ The daily ingestion of bacterial cells by an infant receiving $800 \mathrm{~mL}$ of breast milk would be up to $10^{7}-10^{8}$. 159 Therefore in a recent 12-month longitudinal study, ${ }^{160}$ it was estimated that breast milk accounted for almost one-third of total bacteria present in the gut of breastfed infants during the first month of life. Moreover, metagenome predictions indicated that breast milk harbours bacteria with prominent carbohydrate, amino acid, and energy metabolism functions, suggesting a dual regulatory role of human milk bacteria as a continuous inoculum and on the physiological and metabolic development of neonates via their metabolites.

Introducing bacteria in IF can be a clever way to better adjust IF to breast milk. Such bacteria, called probiotics, are therefore added in IF. 


\section{Probiotics}

Probiotics are defined as "live microorganisms that, when administered in adequate amounts, confer a health benefit on the host". ${ }^{161,162}$ The most commonly probiotics used in infant nutrition are strains of Bifidobacterium (Bifidobacterium infantis, Bifidobacterium lactis, Bifidobacterium longum) and Lactobacillus (Lactobacillus acidophilus, Lactobacillus fermentum, Lactobacillus reuteri, Lactobacillus rhamnosus) isolated from the human gastrointestinal tract, human breast milk or dairy products. ${ }^{141,163}$ The effects of probiotics such as the normalization of perturbed microbiota or the production of SCFAs are widespread among probiotics while particular changes in the microbial composition of the gut are specieor even strain-dependent. ${ }^{162,163}$ Probiotics are usually administered alone or in 2-3 strains combination, far from the microbial diversity of human milk. The efficacy of specific probiotics has been demonstrated for the treatment of acute gastroenteritis and the prevention of necrotizing enterocolitis, antibiotic-associated diarrhoea and nosocomial diarrhoea in infants and children. ${ }^{164,165,166}$

The long-term effects of early probiotic consumption on growth have been investigated in a few studies 2 to 13 years after the intervention. No effect of supplementation with $L$. rhamnosus GG or L. fermentum CECT5716 in the first months of life was observed on growth and microbiota composition at $2,{ }^{167} 3,{ }^{168} 5^{169}$ and 13 years. ${ }^{170}$ In contrast, an impact of maternal probiotic supplementation with L. rhamnosus $G G$ was observed on children's body weight development, with a lesser weight gain until 2-4 years, especially among children who later became overweight, resulting in a lower BMI until 7 years of age. ${ }^{171}$ However, there is no study investigating the effects of probiotic supplementation on metabolic syndrome progression in adulthood. In animal studies, early probiotic administration has been associated with the maintenance of eubiosis, intestinal tract maturation, and improved immunity and reduced pathogen infection. ${ }^{172}$ 
The ESPGHAN Committee on Nutrition concluded in 2011 that the administration of currently evaluated probiotic-supplemented formula to healthy infants did not raise safety concerns with regard to growth and adverse effects. However, because of high variability in responses, probably due to the small size and insufficient statistical power of studies, the different probiotic strains, doses, timing and duration of administration used, the lack of data on the long-term after the cessation of the probiotic and the different methods used for microbiota analysis, the relevance of supplementation of IF with probiotics remains unclear and the routine use of probiotic-supplemented IF is not currently mandatory. ${ }^{141,158,163}$

\section{Synbiotics}

Supplementation of IF with prebiotics or probiotics alone does not fully mimic the complexity of human milk, which provides both, and has some limitations. Probiotics would transiently colonize the infant's gut ${ }^{173}$ (further studies are needed ${ }^{174}$ ) and prebiotics can only have an impact on bacteria that are already present in the gut. Therefore, beneficial synergistic effects may be expected from a combination of probiotics and prebiotics, called synbiotic, using prebiotics to selectively increase abundance of both endogenous beneficial bacteria and probiotics in the infant gut. However, due to the limited available data on synbiotics, the ESPGHAN Committee on Nutrition does not currently recommend the use of IF supplemented with synbiotics even though the available data suggest that they are safe. ${ }^{141}$ Besides, the superiority of synbiotics over probiotics or prebiotics is not yet clearly established. ${ }^{175}$ The impact on microbial profile, particularly the bifidogenic effect, of synbiotic IF containing Lactobacillus reuteri and GOS/FOS, Lactobacillus paracasei and GOS/FOS or Bifidobacterium animalis and bovine milk-derived oligosaccharides did not 
result in any differences in infant growth parameters during the first year of life compared to control IF (without prebiotics and/or probiotics). ${ }^{176,177,149}$

To conclude, even if some prebiotics and/or specific probiotic strains display promising results, more randomized controlled clinical trials with longer follow-up are needed for the determination of tailored combinations and of their physiological and metabolic impact on the host (Fig. 1).

\section{Effects of the infant formula composition on gut microbiota: a possible mechanistic link?}

\section{Early establishment of gut microbiota and differences between formula-fed and breastfed infants}

Recent advances in sequencing technologies of the microbiota have questioned the sterile womb paradigm, suggesting a mother-to-child transfer of commensal bacteria in utero. ${ }^{178,179,180,181}$ If there is currently no clear consensus regarding the prenatal life, it is well established that the first months of life are crucial for the establishment of the gut microbiota and host-microbiota symbiosis. Gut microbiota exerts several functions such as facilitating nutrient utilization, synthesizing amino acids and vitamins, educating the naïve immune system and programming the metabolic system in neonates. ${ }^{8,182,183}$ It modulates infant growth and body composition ${ }^{184,185,186,187}$ and plays a crucial role in lifelong health. In mice, an early exposure to antibiotics during the suckling period was associated with an increased fat mass and a negative modulation of hepatic metabolism in adulthood though gut microbiota was only transiently altered. ${ }^{188}$ Mainly consisting of facultative anaerobes and then obligate anaerobes within the 2 first weeks of life, gut microbiota slowly achieves a more complex structure and evolves towards an adult-like configuration throughout the first three years of 
life. ${ }^{189,190,191}$ Among the influencing factors of gut colonization, early nutrition plays a predominant role. ${ }^{8,192}$ Formula-feeding has been associated with a less stable microbiota over time, different overall bacterial composition and higher bacterial richness and diversity (although controversial) ${ }^{133}$ compared to breastfeeding. ${ }^{193,194,195,196,197}$ However, inconsistencies exist between studies on the impact of formula-feeding on gut microbiota composition and may be explained by several factors such as changes in IF composition over time and differences in oligosaccharides composition between breast milk and IF. ${ }^{163}$ Early gut microbiota may influence later microbiota ${ }^{198,199}$ but the sustainability of early microbiota changes in later infancy and adulthood remains uncertain. ${ }^{148,167}$ In addition, alterations in the gut microbiota profile during the first months of life may precede overweight development. ${ }^{186,200,201,202}$ If the exact role of specific bacterial families or genera is not clear, a higher abundance of the genus Bifidobacterium has been observed during the first year of life in infants who remained normal weight at 7 years compared to children who became overweight. ${ }^{202}$ Infants not primarily breastfed had higher abundance of Bacteroidaceae $e^{160}$ and positive correlations were found between a higher abundance of Bacteroides spp. (in particular B. fragilis) and BMI at the age of 3 and 26 weeks but disappeared at approximately 2.5 years of age. ${ }^{201}$ In overall, these data suggest that gut microbiota primocolonization is crucial and may affect infant growth trajectories. However, further investigations are needed to determine the time length of this early critical window and why early microbiota changes are not always observed in later life.

Beyond the taxonomic level, it is necessary to investigate the infant gut microbiota in terms of functionality since bacteria belonging to different taxonomic groups may perform similar functions. ${ }^{203}$ Formula-fed infants had an accelerated functional maturity compared to breastfed infants, characterized by enrichment in functions characteristic of the adult microbiome at 4 months, despite a small overall functional difference. ${ }^{204,205}$ Formula-fed 20 
infants also had high stool levels of SCFAs such as propionate, butyrate, acetate, 5-aminovalerate and free amino acids at 3 and 6 months of age while breastfed infants had high concentrations of fucosylated oligosaccharides and lactic acid, as a result of a higher fermentation of HMOs. ${ }^{206}$

Gut microbiota can be modulated by the macronutrient composition of IF. A wheypredominant IF led to a faecal microbiota closer to that of breastfed infants at 2 months of age, compared to a casein-predominant IF. ${ }^{207}$ Proteins, such as lactoferrin, may also function as prebiotics and impact gut microbiota composition. ${ }^{208,209}$ The structure of triglycerides could also affect gut microbiota. Indeed, a high $\beta$-palmitate formula was shown to increase Lactobacillus and Bifidobacteria counts in faecal stools of 6 week-old infants at abundances similar to breastfed infants, compared to infants receiving a low $\beta$-palmitate IF. ${ }^{210} \mathrm{~A}$ recent study in a germ-free mice model demonstrated that the fatty acid composition and phospholipid types may differently affect gut microbiota establishment. ${ }^{211}$ The addition of MFGM alone did not lead to changes in gut microbiota composition in 28 day-old piglets compared to standard IF but the addition of both dairy lipids and MFGM affected gut microbiota composition, with an increase in Proteobacteria and a decrease in Firmicutes phyla compared to piglets fed a standard vegetable-oil IF. ${ }^{212}$ These changes were similar to those observed at 3 months of age between breastfed infants and infants fed a vegetable-oil-based $\mathrm{IF}^{213}$

To conclude, relationships have been described between macronutrients and specific bacteria but further studies are needed to better understand them and evaluate their long-term impact on health. ${ }^{159}$ 


\section{Mechanisms linking gut microbiota and long-term health}

Several mechanisms have been proposed to connect gut microbiota to metabolic health. One mechanism relies on the property of gut microbiota to harvest energy in relation with the enrichment of genes coding enzymes that utilize non-digestible dietary carbohydrates to produce SCFAs. Indeed, breast milk butyrate was inversely associated with 12-month skinfolds and BMI, 3-12 month skinfold gain and weight gain in a prospective birth cohort. Associations were also found for acetate and formic acid and BMI and skinfolds at 3 months but not for adiposity at 12 months. ${ }^{214}$ SCFAs are key mediators of the crosstalk between gut microbiota and host cells, able to act as signalling molecules by bonding to their receptors, expressed by different cell types such as enterocytes and intestinal enteroendocrine cells. SCFAs can bind to the free fatty acid receptor (FFAR) 2 and 3 (formerly known as G-protein coupled receptor (GPR) 43 and 41, respectively), the affinity for these receptors depending on the size of their aliphatic tail ${ }^{215,216}$ and stimulate the release of enteroendocrine hormones such as glucagon-like peptide-1 (GLP-1) and peptide YY (PYY). For instance, propionate lowered hepatic glucose production in healthy rats in vivo, ${ }^{217}$ and prevented weight gain in overweigh adult humans $^{218}$ via the stimulation of the release of GLP-1 and PYY. ${ }^{219,220}$ GLP-1 is an incretin exerting several functions, from increasing insulin and decreasing glucagon secretion and stimulating beta-cell growth to decreasing appetite and food intake. GLP-1 secretion is not only stimulated by SCFAs but also by the digestion of macronutrients. ${ }^{221,222,223,224}$

Bacteria and their metabolites (SCFAs but also other signalling molecules) may also regulate the expression of key regulatory and functional genes such as those that are important for fat storage (adipocyte development and lipolysis) and oxidation, and gastrointestinal hormone production. ${ }^{225}$ For instance, butyrate inhibited intestinal cholesterol biosynthesis in vitro, thus possibly lowering plasma cholesterol levels ${ }^{226}$ and improved insulin sensitivity in mice, through the promotion of energy expenditure and induction of mitochondrial 
function. ${ }^{227}$ SCFAs also regulate leptin secretion by adipocytes. ${ }^{228,229}$ SCFAs may therefore be mediators of the long-term effects exerted by early nutrition.

Host-microbiota interactions could also be mediated by other mechanisms. Diverse metabolites and signalling molecules produced by gut microbiota such as SCFAS and folate may directly or indirectly modify the epigenome and therefore regulate host genes and shape long-term phenotype. ${ }^{230,231}$ There are three distinct epigenetic mechanisms: DNA methylation, histone modifications and non-coding microRNAs (miRNAs). Epigenome and microbiome would be interrelated and influenced by each other but their interaction in responses to earlylife environment remain unclear. ${ }^{232,233}$ SCFAs, such as butyrate and propionate are thought to modulate host cellular processes through inhibition of histone deacetylase activity and to alter the expression of specific genes. ${ }^{234,235,236}$ Interactions between gut microbiota composition and epigenetic regulation of genes have been demonstrated in obese and diabetic adult patients with a significant correlation between a higher BMI and lower methylation of FFAR3. ${ }^{237}$ In a germ-free mice model, supplementation with SCFAs was sufficient to recapitulate chromatin modification states and transcriptional responses associated with colonization. $^{238}$ Besides, a clear association has been demonstrated in pregnant women between a microbiome dominated by Firmicutes and blood DNA methylation patterns, associated with greater susceptibility to diseases such as cardiovascular disease and obesity. ${ }^{239}$ Breastfeeding would contribute, via the modulation of gut microbiota composition, to the production of larger amounts of folate, inducing DNA methylation marks. On the contrary, the higher protein content of infant IF may lead to a higher amount of protein reaching the colon and therefore to an enrichment in proteolytic bacteria, producing butyrate, at the expense of carbohydrate-fermenting bacteria, promoting histone acetylation, known to be a key factor of epigenetic regulation of cholesterol and lipid metabolism. ${ }^{240}$ Other nutrients such as LC-PUFAs may also have an effect on epigenetic processes. ${ }^{241,242}$ Thus, both the 
supplementation of IF with probiotics and prebiotics and its composition in macronutrients may induce epigenetic modifications by impacting gut microbiota composition and metabolism.

Early life nutrition may also alter miRNA profiles and therefore gene expression since miRNA expression depends on gut microbiota community. ${ }^{231,243,244}$ Human and bovine milks contain miRNAs and so do IF but with much lower expression. ${ }^{245,246,247,248}$

Targeting gut microbiota seems to be relevant to prevent metabolic diseases on the longterm. Integrative approaches of metagenomic, epigenetic and metabolomic/lipidomic data are necessary to better understand their dynamic interactions with early-life environment and improve long-term health (Fig. 2).

\section{Conclusion}

Early nutrition plays a predominant role in health and well-being of the newborn and in later life by modulating its metabolism. Improving the functional effects of IF to reduce the gap between breastfed and formula-fed infants is crucial and has been the topic of great research over the past years. Yet, numerous questions remain to be answered about which components should be added to IF and in which quantity depending on their metabolic fate and outcomes. Indeed, when it comes to human milk composition and infant nutrition in general, there is no "one-size-fits-all construct". ${ }^{127}$ Regarding metabolic health of infants, an improved IF would consist in modulating all macronutrients: proteins (to decrease the quantity but mostly improve their quality), lipids (to resemble the size, structure and composition of the fat globule by the addition of dairy lipids, cholesterol and MFGM, and also a balanced $\omega 3: \omega 6$ LC-PUFA ratio) and to supplement with prebiotics, probiotics or synbiotics. However, further studies are needed to improve IF composition and gain comprehension on how it may modulate the interplay between host metabolism and gut 24 
microbiome and exert long-term health benefits. Gut microbiota development plays a key role but due to its complexity, the underlying pathways impacting the infant biology remain largely unknown. Animals such as the nonhuman primate and the neonatal piglet, excellent preclinical models for the human infant, ${ }^{93,249}$ proved to be useful to control and account for some confounding factors found in human studies and to investigate the mechanisms involved in the long-term effects of early nutrition. They allow for the screening of potential nutritional factors and the selection of the most promising ones. Yet there is still a need for a standardized model for infant growth and development. Besides, they remain models and additional well-designed longitudinal human studies are needed to investigate the effects of the IF composition on host metabolism beyond infancy.

\section{Acknowledgements}

The authors thank Dr Alain Dabadie for his careful reading of the manuscript and for his constructive remarks.

\section{Financial Support}

M.L. is employed by Lactalis R\&D.

\section{Conflicts of Interest}

None. 


\section{References}

1. WHO, World Health Organization. Media centre - Obesity and overweight. Available from: www.who.int/mediacentre/factsheets/fs311/en/. 2016, Accessed July 2017.

2. Hales CN, Barker DJ. Type 2 (non-insulin-dependent) diabetes mellitus: the thrifty phenotype hypothesis. Diabetologia. 1992; 35, 595-601.

3. Mcmillen IC, Robinson JS. Developmental Origins of the Metabolic Syndrome: Prediction, Plasticity, and Programming. Physiological Reviews. 2005; 85, 571-633.

4. Nauta AJ, Ben Amor K, Knol J, Garssen J, van der Beek EM. Relevance of pre- and postnatal nutrition to development and interplay between the microbiota and metabolic and immune systems. The American journal of clinical nutrition. 2013; 98, 586S593S.

5. Thompson AL. Developmental origins of obesity: early feeding environments, infant growth, and the intestinal microbiome. Am J Hum Biol. 2012; 24, 350-360.

6. CDC, Centers for Disease Control and Prevention. Breastfeeding Report Card 2016. Available from: www.cdc.gov/breastfeeding/data/reportcard.htm. 2016, Accessed July 2017.

7. Victora CG, Bahl R, Barros AJ, et al. Breastfeeding in the 21st century: epidemiology, mechanisms, and lifelong effect. Lancet. 2016; 387, 475-490.

8. Wang M, Monaco MH, Donovan SM. Impact of early gut microbiota on immune and metabolic development and function. Semin Fetal Neonatal Med. 2016; 21, 380-387.

9. Johnson CC, Ownby DR. The infant gut bacterial microbiota and risk of pediatric asthma and allergic diseases. Transl Res. 2017; 179, 60-70.

10. Dominguez PR. The study of postnatal and later development of the taste and olfactory systems using the human brain mapping approach: an update. Brain Res Bull. 2011; 84, 118-124.

11. Nicklaus S, Remy E. Early Origins of Overeating: Tracking Between Early Food Habits and Later Eating Patterns. Current Obesity Reports. 2013; 2, 179-184.

12. Mennella JA. Ontogeny of taste preferences: basic biology and implications for health. Am J Clin Nutr. 2014; 99, 704S-711S.

13. Mennella JA, Reiter AR, Daniels LM. Vegetable and Fruit Acceptance during Infancy: Impact of Ontogeny, Genetics, and Early Experiences. Adv Nutr. 2016; 7 , 211S-219S.

14. Koletzko B, Brands B, Grote V, et al. Long-Term Health Impact of Early Nutrition: The Power of Programming. Ann Nutr Metab. 2017; 70, 161-169.

15. Gruszfeld D, Socha P. Early nutrition and health: short- and long-term outcomes. World Rev Nutr Diet. 2013; 108, 32-39.

16. Andersen LG, Holst C, Michaelsen KF, Baker JL, Sorensen TI. Weight and weight gain during early infancy predict childhood obesity: a case-cohort study. International journal of obesity. 2012; 36, 1306-1311.

17. Druet C, Stettler N, Sharp S, et al. Prediction of childhood obesity by infancy weight gain: an individual-level meta-analysis. Paediatr Perinat Epidemiol. 2012; 26, 19-26.

18. Botton J, Heude B, Maccario J, Ducimetiere P, Charles MA. Postnatal weight and height growth velocities at different ages between birth and $5 \mathrm{y}$ and body composition in adolescent boys and girls. Am J Clin Nutr. 2008; 87, 1760-1768.

19. Chomtho S, Wells JC, Williams JE, et al. Infant growth and later body composition: evidence from the 4-component model. Am J Clin Nutr. 2008; 87, 1776-1784. 
20. Rolland-Cachera MF, Deheeger M, Maillot M, Bellisle F. Early adiposity rebound: causes and consequences for obesity in children and adults. Int J Obes (Lond). 2006; 30, S11-17.

21. Ailhaud G, Massiera F, Weill P, et al. Temporal changes in dietary fats: role of n-6 polyunsaturated fatty acids in excessive adipose tissue development and relationship to obesity. Prog Lipid Res. 2006; 45, 203-236.

22. Dewey KG, Heinig MJ, Nommsen LA, Peerson JM, Lonnerdal B. Growth of breastfed and formula-fed infants from 0 to 18 months: the DARLING Study. Pediatrics. 1992; 89, 1035-1041.

23. Johnson L, van Jaarsveld CH, Llewellyn CH, Cole TJ, Wardle J. Associations between infant feeding and the size, tempo and velocity of infant weight gain: SITAR analysis of the Gemini twin birth cohort. Int J Obes (Lond). 2014; 38, 980-987.

24. Hawley NL, Johnson W, Nu'usolia O, McGarvey ST. The contribution of feeding mode to obesogenic growth trajectories in American Samoan infants. Pediatr Obes. 2014; 9, e1-e13.

25. Imai CM, Gunnarsdottir I, Thorisdottir B, Halldorsson TI, Thorsdottir I. Associations between infant feeding practice prior to six months and body mass index at six years of age. Nutrients. 2014; 6, 1608-1617.

26. Mihrshahi S, Battistutta D, Magarey A, Daniels LA. Determinants of rapid weight gain during infancy: baseline results from the NOURISH randomised controlled trial. BMC Pediatr. 2011; 11, 99.

27. Rzehak P, Oddy WH, Mearin ML, et al. Infant feeding and growth trajectory patterns in childhood and body composition in young adulthood. Am J Clin Nutr. 2017; 106, 568-580.

28. Bell KA, Wagner CL, Feldman HA, Shypailo RJ, Belfort MB. Associations of infant feeding with trajectories of body composition and growth. Am J Clin Nutr. 2017; 106, 491-498.

29. Arenz S, Ruckerl R, Koletzko B, von Kries R. Breast-feeding and childhood obesity-a systematic review. Int J Obes Relat Metab Disord. 2004; 28, 1247-1256.

30. Horta BL, Loret de Mola C, Victora CG. Long-term consequences of breastfeeding on cholesterol, obesity, systolic blood pressure and type 2 diabetes: a systematic review and meta-analysis. Acta Paediatr. 2015; 104, 30-37.

31. Rossiter MD, Colapinto CK, Khan MK, et al. Breast, Formula and Combination Feeding in Relation to Childhood Obesity in Nova Scotia, Canada. Matern Child Health J. 2015; 19, 2048-56.

32. Kramer MS, Matush L, Vanilovich I, et al. A randomized breast-feeding promotion intervention did not reduce child obesity in Belarus. J Nutr. 2009; 139, 417S-421S.

33. Coppi S, Iacoponi F, Fommei C, Strambi M. Growth trend during the first six months of life in male infants with different type of feeding. Minerva pediatrica. 2013; 65, 5159.

34. van der Willik EM, Vrijkotte TG, Altenburg TM, Gademan MG, Kist-van Holthe J. Exclusively breastfed overweight infants are at the same risk of childhood overweight as formula fed overweight infants. Arch Dis Child. 2015; 100, 932-7..

35. Betoko A, Charles MA, Hankard R, et al. Determinants of infant formula use and relation with growth in the first 4 months. Maternal \& Child Nutrition. 2014; 10, $267-$ 279.

36. Uwaezuoke SN, Eneh CI, Ndu IK. Relationship Between Exclusive Breastfeeding and Lower Risk of Childhood Obesity: A Narrative Review of Published Evidence. Clin Med Insights Pediatr. 2017; 11, 1179556517690196. 
37. Beyerlein A, von Kries R. Breastfeeding and body composition in children: will there ever be conclusive empirical evidence for a protective effect against overweight? Am J Clin Nutr. 2011; 94, 1772S-1775S.

38. Ong KK, Petry CJ, Emmett PM, et al. Insulin sensitivity and secretion in normal children related to size at birth, postnatal growth, and plasma insulin-like growth factor-I levels. Diabetologia. 2004; 47, 1064-1070.

39. Owen CG, Martin RM, Whincup PH, Smith GD, Cook DG. Does breastfeeding influence risk of type 2 diabetes in later life? A quantitative analysis of published evidence. Am J Clin Nutr. 2006; 84, 1043-1054.

40. Hui LL, Kwok MK, Nelson EAS, et al. The association of breastfeeding with insulin resistance at 17 years: Prospective observations from Hong Kong's "Children of 1997" birth cohort. Matern Child Nutr. 2017 [Epub ahead of print].

41. Axelsson IE, Ivarsson SA, Raiha NC. Protein intake in early infancy: effects on plasma amino acid concentrations, insulin metabolism, and growth. Pediatr Res. 1989; 26, 614-617.

42. Manco M, Alterio A, Bugianesi E, et al. Insulin dynamics of breast- or formula-fed overweight and obese children. Journal of the American College of Nutrition. 2011; 30, 29-38.

43. Lucas A, Sarson DL, Blackburn AM, et al. Breast vs bottle: endocrine responses are different with formula feeding. Lancet. 1980; 1, 1267-1269.

44. Newgard CB, An J, Bain JR, et al. A branched-chain amino acid-related metabolic signature that differentiates obese and lean humans and contributes to insulin resistance. Cell Metab. 2009; 9, 311-326.

45. O'Sullivan A, He X, McNiven EM, et al. Early diet impacts infant rhesus gut microbiome, immunity, and metabolism. J Proteome Res. 2013; 12, 2833-2845.

46. Socha P, Grote V, Gruszfeld D, et al. Milk protein intake, the metabolic-endocrine response, and growth in infancy: data from a randomized clinical trial. Am J Clin Nutr. 2011; 94, 1776S-1784S.

47. Wallensteen M, Lindblad BS, Zetterstrom R, Persson B. Acute C-peptide, insulin and branched chain amino acid response to feeding in formula and breast fed infants. Acta Paediatr Scand. 1991; 80, 143-148.

48. Tikanoja T, Simell O, Viikari M, Jarvenpaa AL. Plasma amino acids in term neonates after a feed of human milk or formula. II. Characteristic changes in individual amino acids. Acta Paediatr Scand. 1982; 71, 391-397.

49. Janas LM, Picciano MF, Hatch TF. Indices of protein metabolism in term infants fed human milk, whey-predominant formula, or cow's milk formula. Pediatrics. 1985; 75, 775-784.

50. Wang TJ, Larson MG, Vasan RS, et al. Metabolite profiles and the risk of developing diabetes. Nat Med. 2011; 17, 448-453.

51. Roszkowska R, Taranta-Janusz K, Tenderenda-Banasiuk E, Wasilewska A. Increased circulating inflammatory markers may indicate that formula-fed children are at risk of atherosclerosis. Acta Paediatr. 2014; 103, e354-358.

52. Wilson AC, Forsyth JS, Greene SA, et al. Relation of infant diet to childhood health: seven year follow up of cohort of children in Dundee infant feeding study. BMJ. 1998; 316, 21-25.

53. Taittonen L, Nuutinen M, Turtinen J, Uhari M. Prenatal and postnatal factors in predicting later blood pressure among children: cardiovascular risk in young Finns. Pediatr Res. 1996; 40, 627-632. 
54. Ramirez-Silva I, Rivera JA, Trejo-Valdivia B, et al. Breastfeeding status at age 3 months is associated with adiposity and cardiometabolic markers at age 4 years in mexican children. J Nutr. 2015; 145, 1295-1302.

55. Owen CG, Whincup PH, Odoki K, Gilg JA, Cook DG. Infant feeding and blood cholesterol: a study in adolescents and a systematic review. Pediatrics. 2002; 110, 597-608.

56. Wu TC, Huang IF, Chen YC, Chen PH, Yang LY. Differences in serum biochemistry between breast-fed and formula-fed infants. J Chin Med Assoc. 2011; 74, 511-515.

57. Owen CG, Whincup PH, Cook DG. Breast-feeding and cardiovascular risk factors and outcomes in later life: evidence from epidemiological studies. Proc Nutr Soc. 2011; 70, 478-484.

58. Ronis MJ, Chen Y, Shankar K, et al. Formula feeding alters hepatic gene expression signature, iron and cholesterol homeostasis in the neonatal pig. Physiol Genomics. 2011; 43, 1281-1293.

59. Izadi V, Kelishadi R, Qorbani M, et al. Duration of breast-feeding and cardiovascular risk factors among Iranian children and adolescents: the CASPIAN III study. Nutrition. 2013; 29, 744-751.

60. Martin RM, Patel R, Kramer MS, et al. Effects of Promoting Longer Term and Exclusive Breastfeeding on Cardiometabolic Risk Factors at Age 11.5 Years: A Cluster-Randomized, Controlled Trial. Circulation. 2014; 129, 321-329.

61. Martin RM, Ben-Shlomo Y, Gunnell D, et al. Breast feeding and cardiovascular disease risk factors, incidence, and mortality: the Caerphilly study. J Epidemiol Community Health. 2005; 59, 121-129.

62. Hamosh M. Bioactive factors in human milk. Pediatr Clin North Am. 2001; 48, 69-86.

63. Schack-Nielsen L, Michaelsen KF. Advances in our understanding of the biology of human milk and its effects on the offspring. J Nutr. 2007; 137, 503S-510S.

64. Gidrewicz DA, Fenton TR. A systematic review and meta-analysis of the nutrient content of preterm and term breast milk. BMC Pediatr. 2014; 14, 216.

65. Mace K, Steenhout P, Klassen P, Donnet A. Protein quality and quantity in cow's milk-based formula for healthy term infants: past, present and future. Nestle Nutr Workshop Ser Pediatr Program. 2006; 58, 189-203.

66. Alexy U, Kersting M, Sichert-Hellert W, Manz F, Schoch G. Macronutrient intake of 3- to 36-month-old German infants and children: results of the DONALD Study. Dortmund Nutritional and Anthropometric Longitudinally Designed Study. Ann Nutr Metab. 1999; 43, 14-22.

67. Heinig MJ, Nommsen LA, Peerson JM, Lonnerdal B, Dewey KG. Energy and protein intakes of breast-fed and formula-fed infants during the first year of life and their association with growth velocity: the DARLING Study. Am J Clin Nutr. 1993; 58, 152-161.

68. Escribano J, Luque V, Ferre N, et al. Effect of protein intake and weight gain velocity on body fat mass at 6 months of age: the EU Childhood Obesity Programme. International journal of obesity. 2012; 36, 548-553.

69. Rolland-Cachera MF, Deheeger M, Akrout M, Bellisle F. Influence of macronutrients on adiposity development: a follow up study of nutrition and growth from 10 months to 8 years of age. Int J Obes Relat Metab Disord. 1995; 19, 573-578.

70. Gruszfeld D, Weber M, Gradowska K, et al. Association of early protein intake and pre-peritoneal fat at five years of age: Follow-up of a randomized clinical trial. Nutr Metab Cardiovasc Dis. 2016; 26, 824-832. 
71. Voortman T, Braun KV, Kiefte-de Jong JC, et al. Protein intake in early childhood and body composition at the age of 6 years: The Generation R Study. Int J Obes (Lond). 2016; 40, 1018-1025.

72. Koletzko B, Chourdakis M, Grote V, et al. Regulation of early human growth: impact on long-term health. Ann Nutr Metab. 2014; 65, 101-109.

73. Savino F, Fissore MF, Grassino EC, et al. Ghrelin, leptin and IGF-I levels in breastfed and formula-fed infants in the first years of life. Acta Paediatr. 2005; 94, 531-537.

74. Chellakooty M, Juul A, Boisen KA, et al. A prospective study of serum insulin-like growth factor I (IGF-I) and IGF-binding protein-3 in 942 healthy infants: associations with birth weight, gender, growth velocity, and breastfeeding. J Clin Endocrinol Metab. 2006; 91, 820-826.

75. Martin RM, Holly JM, Smith GD, et al. Could associations between breastfeeding and insulin-like growth factors underlie associations of breastfeeding with adult chronic disease? The Avon Longitudinal Study of Parents and Children. Clin Endocrinol (Oxf). 2005; 62, 728-737.

76. Hornell A, Lagstrom H, Lande B, Thorsdottir I. Protein intake from 0 to 18 years of age and its relation to health: a systematic literature review for the 5th Nordic Nutrition Recommendations. Food Nutr Res. 2013; 57.

77. Patro-Golab B, Zalewski BM, Kouwenhoven SM, et al. Protein Concentration in Milk Formula, Growth, and Later Risk of Obesity: A Systematic Review. J Nutr. 2016; 146, 551-564.

78. Davis AM, Harris BJ, Lien EL, Pramuk K, Trabulsi J. Alpha-lactalbumin-rich infant formula fed to healthy term infants in a multicenter study: plasma essential amino acids and gastrointestinal tolerance. Eur J Clin Nutr. 2008; 62, 1294-1301.

79. Sandstrom O, Lonnerdal B, Graverholt G, Hernell O. Effects of alpha-lactalbuminenriched formula containing different concentrations of glycomacropeptide on infant nutrition. Am J Clin Nutr. 2008; 87, 921-928.

80. Fazzolari-Nesci A, Domianello D, Sotera V, Raiha NC. Tryptophan fortification of adapted formula increases plasma tryptophan concentrations to levels not different from those found in breast-fed infants. J Pediatr Gastroenterol Nutr. 1992; 14, 456459.

81. Menezes JS, Mucida DS, Cara DC, et al. Stimulation by food proteins plays a critical role in the maturation of the immune system. Int Immunol. 2003; 15, 447-455.

82. Koletzko B, von Kries R, Closa R, et al. Lower protein in infant formula is associated with lower weight up to age 2 y: a randomized clinical trial. Am J Clin Nutr. 2009; 89, 1836-1845.

83. Koletzko B, Beyer J, Brands B, et al. Early influences of nutrition on postnatal growth. Nestle Nutrition Institute workshop series. 2013; 71, 11-27.

84. Weber M, Grote V, Closa-Monasterolo R, et al. Lower protein content in infant formula reduces BMI and obesity risk at school age: follow-up of a randomized trial. Am J Clin Nutr. 2014; 99, 1041-1051.

85. Putet G, Labaune JM, Mace K, et al. Effect of dietary protein on plasma insulin-like growth factor-1, growth, and body composition in healthy term infants: a randomised, double-blind, controlled trial (Early Protein and Obesity in Childhood (EPOCH) study). Br J Nutr. 2016; 115, 271-284.

86. Koletzko B, von Kries R, Closa R, et al. Can infant feeding choices modulate later obesity risk? Am J Clin Nutr. 2009; 89, 1502S-1508S.

87. Greer FR, Kleinman RE. An infant formula with decreased weight gain and higher IQ: are we there yet? The American journal of clinical nutrition. 2014; 99, 757-758. 
88. Satue-Gracia MT, Frankel EN, Rangavajhyala N, German JB. Lactoferrin in infant formulas: effect on oxidation. J Agric Food Chem. 2000; 48, 4984-4990.

89. Fields DA, Schneider CR, Pavela G. A narrative review of the associations between six bioactive components in breast milk and infant adiposity. Obesity (Silver Spring). 2016; 24, 1213-1221.

90. Ballard O, Morrow AL. Human milk composition: nutrients and bioactive factors. Pediatr Clin North Am. 2013; 60, 49-74.

91. Catli G, Olgac Dundar N, Dundar BN. Adipokines in breast milk: an update. J Clin Res Pediatr Endocrinol. 2014; 6, 192-201.

92. Badillo-Suarez PA, Rodriguez-Cruz M, Nieves-Morales X. Impact of Metabolic Hormones Secreted in Human Breast Milk on Nutritional Programming in Childhood Obesity. J Mammary Gland Biol Neoplasia. 2017 [Epub ahead of print].

93. Donovan SM. The Role of Lactoferrin in Gastrointestinal and Immune Development and Function: A Preclinical Perspective. J Pediatr. 2016; 173, S16-28.

94. Flachs P, Rossmeisl M, Bryhn M, Kopecky J. Cellular and molecular effects of n-3 polyunsaturated fatty acids on adipose tissue biology and metabolism. Clin Sci (Lond). 2009; 116, 1-16.

95. Oosting A, Kegler D, Boehm G, et al. N-3 long-chain polyunsaturated fatty acids prevent excessive fat deposition in adulthood in a mouse model of postnatal nutritional programming. Pediatr Res. 2010; 68, 494-499.

96. Oosting A, Kegler D, van de Heijning BJ, Verkade HJ, van der Beek EM. Reduced linoleic acid intake in early postnatal life improves metabolic outcomes in adult rodents following a Western-style diet challenge. Nutr Res. 2015; 35, 800-811.

97. Schipper L, Bouyer K, Oosting A, Simerly RB, van der Beek EM. Postnatal dietary fatty acid composition permanently affects the structure of hypothalamic pathways controlling energy balance in mice. Am J Clin Nutr. 2013; 98, 1395-1401.

98. Massiera F, Saint-Marc P, Seydoux J, et al. Arachidonic acid and prostacyclin signaling promote adipose tissue development: a human health concern? J Lipid Res. 2003; 44, 271-279.

99. Patro-Golab B, Zalewski BM, Kolodziej M, et al. Nutritional interventions or exposures in infants and children aged up to 3 years and their effects on subsequent risk of overweight, obesity and body fat: a systematic review of systematic reviews. Obes Rev. 2016; 17, 1245-1257.

100. Forsyth JS, Willatts P, Agostoni C, et al. Long chain polyunsaturated fatty acid supplementation in infant formula and blood pressure in later childhood: follow up of a randomised controlled trial. BMJ. 2003; 326:953.

101. Delplanque B, Gibson R, Koletzko B, Lapillonne A, Strandvik B. Lipid Quality in Infant Nutrition: Current Knowledge and Future Opportunities. $J$ Pediatr Gastroenterol Nutr. 2015; 61, 8-17.

102. Colombo J, Jill Shaddy D, Kerling EH, Gustafson KM, Carlson SE. Docosahexaenoic acid (DHA) and arachidonic acid (ARA) balance in developmental outcomes. Prostaglandins Leukot Essent Fatty Acids. 2017; 121, 52-56.

103. European Commission: Commission Delegated Regulation (EU) 2016/127 of 25 September 2015 supplementing Regulation (EU) No 609/2013 of the European Parliament and of the Council as regards the specific compositional and information requirements for infant formula and follow-on formula and as regards requirements on information relating to infant and young child feeding. Official Journal of the European Union 2016:L25/1. 
104. Koletzko B, Carlson SE, van Goudoever JB. Should Infant Formula Provide Both Omega-3 DHA and Omega-6 Arachidonic Acid? Ann Nutr Metab. 2015; 66, 137-138.

105. Jasani B, Simmer K, Patole SK, Rao SC. Long chain polyunsaturated fatty acid supplementation in infants born at term. Cochrane Database Syst Rev. 2017; 3, CD000376.

106. Koletzko B. Human Milk Lipids. Ann Nutr Metab. 2016; 69, 28-40.

107. Hernell O, Timby N, Domellof M, Lonnerdal B. Clinical Benefits of Milk Fat Globule Membranes for Infants and Children. J Pediatr. 2016; 173, S60-65.

108. Lopez C, Cauty C, Guyomarc'h F. Organization of lipids in milks, infant milk formulas and various dairy products: role of technological processes and potential impacts. Dairy Sci Technol. 2015; 95, 863-893.

109. Cilla A, Diego Quintaes K, Barbera R, Alegria A. Phospholipids in Human Milk and Infant Formulas: Benefits and Needs for Correct Infant Nutrition. Crit Rev Food Sci Nutr. 2016; 56, 1880-1892.

110. Timby N, Lonnerdal B, Hernell O, Domellof M. Cardiovascular risk markers until 12 mo of age in infants fed a formula supplemented with bovine milk fat globule membranes. Pediatr Res. 2014; 76, 394-400.

111. Lukoyanova O, Borovik T, Bushueva, et al. The lipid metabolism in infants fed formula supplemented with bovine milk fat and bovine milk fat globule membranes [abstract]. In: Abstracts of the 50th Annual Meeting of the European Society for Paediatric Gastroenterology, Hepatology and Nutrition; 2017 May 10-13; Prague. ESPGHAN; 2017. Abstract nr 576.

112. Oosting A, Kegler D, Wopereis HJ, et al. Size and phospholipid coating of lipid droplets in the diet of young mice modify body fat accumulation in adulthood. Pediatric research. 2012; 72, 362-369.

113. Oosting A, van Vlies N, Kegler D, et al. Effect of dietary lipid structure in early postnatal life on mouse adipose tissue development and function in adulthood. $\mathrm{Br} J$ Nutr. 2014; 111, 215-226.

114. Baars A, Oosting A, Engels E, et al. Milk fat globule membrane coating of large lipid droplets in the diet of young mice prevents body fat accumulation in adulthood. $\mathrm{Br} J$ Nutr. 2016; 115, 1930-1937.

115. Shek L, Winokan A, Abrahamse-Berkeveld, et al. An innovative infant milk formula with large, phospholipid-coated lipid droplets supports an adequate growth and is well-tolerated in healthy, term Asian infants [abstract]. In: Abstracts of the 4th International Conference on Nutrition \& Growth; 2017 March 2-4; Amsterdam. N\&G; 2017. Abstract nr 71.

116. Gianni ML, Roggero P, Baudry C, Le Ruyet P, Mosca F. Dairy lipids in infant formula: impact on growth and gastrointestinal tolerance in healthy infants [abstract]. In: Abstracts of the 49th Annual Meeting of the European Society for Paediatric Gastroenterology, Hepatology and Nutrition; 2016 May 25-28; Athens. ESPGHAN; 2016. Abstract nr 406.

117. Bayley TM, Alasmi M, Thorkelson T, et al. Longer term effects of early dietary cholesterol level on synthesis and circulating cholesterol concentrations in human infants. Metabolism. 2002; 51, 25-33.

118. Demmers TA, Jones PJ, Wang Y, et al. Effects of early cholesterol intake on cholesterol biosynthesis and plasma lipids among infants until 18 months of age. Pediatrics. 2005; 115, 1594-1601.

119. Ostlund RE, Jr., Lin X. Regulation of cholesterol absorption by phytosterols. Curr Atheroscler Rep. 2006; 8, 487-491. 
120. Claumarchirant L, Matencio E, Sanchez-Siles LM, Alegria A, Lagarda MJ. Sterol Composition in Infant Formulas and Estimated Intake. J Agric Food Chem. 2015; 63, 7245-7251.

121. Nommsen LA, Lovelady CA, Heinig MJ, Lonnerdal B, Dewey KG. Determinants of energy, protein, lipid, and lactose concentrations in human milk during the first 12 mo of lactation: the DARLING Study. Am J Clin Nutr. 1991; 53, 457-465.

122. Srinivasan M, Laychock SG, Hill DJ, Patel MS. Neonatal nutrition: metabolic programming of pancreatic islets and obesity. Exp Biol Med (Maywood). 2003; 228, $15-23$.

123. Bode L. Human milk oligosaccharides: every baby needs a sugar mama. Glycobiology. 2012; 22, 1147-1162.

124. Bode L. The functional biology of human milk oligosaccharides. Early Hum Dev. 2015; 91, 619-622.

125. Jost T, Lacroix C, Braegger C, Chassard C. Impact of human milk bacteria and oligosaccharides on neonatal gut microbiota establishment and gut health. Nutr Rev. 2015; 73, 426-437.

126. Chichlowski M, German JB, Lebrilla CB, Mills DA. The influence of milk oligosaccharides on microbiota of infants: opportunities for formulas. Annu Rev Food Sci Technol. 2011; 2, 331-351.

127. McGuire MK, Meehan CL, McGuire MA, et al. What's normal? Oligosaccharide concentrations and profiles in milk produced by healthy women vary geographically. Am J Clin Nutr. 2017; 105, 1086-1100.

128. Sela DA, Mills DA. Nursing our microbiota: molecular linkages between bifidobacteria and milk oligosaccharides. Trends Microbiol. 2010; 18, 298-307.

129. Yu ZT, Chen C, Newburg DS. Utilization of major fucosylated and sialylated human milk oligosaccharides by isolated human gut microbes. Glycobiology. 2013; 23, 12811292.

130. Aakko J, Kumar H, Rautava S, et al. Human milk oligosaccharide categories define the microbiota composition in human colostrum. Benef Microbes. 2017; 8, 563-567.

131. Lewis ZT, Totten SM, Smilowitz JT, et al. Maternal fucosyltransferase 2 status affects the gut bifidobacterial communities of breastfed infants. Microbiome. 2015; 3, 13.

132. Smith-Brown P, Morrison M, Krause L, Davies PS. Mothers Secretor Status Affects Development of Childrens Microbiota Composition and Function: A Pilot Study. PLoS One. 2016; 11, e0161211.

133. Wang M, Li M, Wu S, et al. Fecal microbiota composition of breast-fed infants is correlated with human milk oligosaccharides consumed. J Pediatr Gastroenterol Nutr. $2015 ; 60,825-833$.

134. Holscher HD, Davis SR, Tappenden KA. Human milk oligosaccharides influence maturation of human intestinal Caco-2Bbe and HT-29 cell lines. J Nutr. 2014; 144, 586-591.

135. Chichlowski M, De Lartigue G, German JB, Raybould HE, Mills DA. Bifidobacteria isolated from infants and cultured on human milk oligosaccharides affect intestinal epithelial function. J Pediatr Gastroenterol Nutr. 2012; 55, 321-327.

136. Kuntz S, Rudloff S, Kunz C. Oligosaccharides from human milk influence growthrelated characteristics of intestinally transformed and non-transformed intestinal cells. Br J Nutr. 2008; 99, 462-471.

137. Ruhaak LR, Stroble C, Underwood MA, Lebrilla CB. Detection of milk oligosaccharides in plasma of infants. Anal Bioanal Chem. 2014; 406, 5775-5784. 
138. Goehring KC, Kennedy AD, Prieto PA, Buck RH. Direct evidence for the presence of human milk oligosaccharides in the circulation of breastfed infants. PLoS One. 2014; 9, e101692.

139. Alderete TL, Autran C, Brekke BE, et al. Associations between human milk oligosaccharides and infant body composition in the first 6 mo of life. Am J Clin Nutr. 2015; 102, 1381-1388.

140. Gibson GR, Hutkins R, Sanders ME, et al. Expert consensus document: The International Scientific Association for Probiotics and Prebiotics (ISAPP) consensus statement on the definition and scope of prebiotics. Nat Rev Gastroenterol Hepatol. 2017; 14, 491-502.

141. Braegger C, Chmielewska A, Decsi T, et al. Supplementation of infant formula with probiotics and/or prebiotics: a systematic review and comment by the ESPGHAN committee on nutrition. J Pediatr Gastroenterol Nutr. 2011; 52, 238-250.

142. Rao S, Srinivasjois R, Patole S. Prebiotic supplementation in full-term neonates: a systematic review of randomized controlled trials. Arch Pediatr Adolesc Med. 2009; 163, 755-764.

143. Canfora EE, Jocken JW, Blaak EE. Short-chain fatty acids in control of body weight and insulin sensitivity. Nat Rev Endocrinol. 2015; 11, 577-591.

144. Priyadarshini M, Thomas A, Reisetter AC, et al. Maternal short-chain fatty acids are associated with metabolic parameters in mothers and newborns. Transl Res. 2014; $164,153-157$.

145. Closa-Monasterolo R, Gispert-Llaurado M, Luque V, et al. Safety and efficacy of inulin and oligofructose supplementation in infant formula: results from a randomized clinical trial. Clin Nutr. 2013; 32, 918-927.

146. Veereman-Wauters G, Staelens S, Van de Broek H, et al. Physiological and bifidogenic effects of prebiotic supplements in infant formulae. $J$ Pediatr Gastroenterol Nutr. 2011; 52, 763-771.

147. Ashley C, Johnston WH, Harris CL, et al. Growth and tolerance of infants fed formula supplemented with polydextrose (PDX) and/or galactooligosaccharides (GOS): double-blind, randomized, controlled trial. Nutrition journal. 2012; 11, 38.

148. Salvini F, Riva E, Salvatici E, et al. A specific prebiotic mixture added to starting infant formula has long-lasting bifidogenic effects. J Nutr. 2011; 141, 1335-1339.

149. Simeoni U, Berger B, Junick J, et al. Gut microbiota analysis reveals a marked shift to bifidobacteria by a starter infant formula containing a synbiotic of bovine milk-derived oligosaccharides and Bifidobacterium animalis subsp. lactis CNCM I-3446. Environ Microbiol. 2016; 18, 2185-2195.

150. Newburg DS, Ruiz-Palacios GM, Altaye M, et al. Innate protection conferred by fucosylated oligosaccharides of human milk against diarrhea in breastfed infants. Glycobiology. 2004; 14, 253-263.

151. Puccio G, Alliet P, Cajozzo C, et al. Effects of Infant Formula With Human Milk Oligosaccharides on Growth and Morbidity: A Randomized Multicenter Trial. $J$ Pediatr Gastroenterol Nutr. 2017; 64, 624-631.

152. Steenhout P, Sperisen P, Martin F-P, et al. Term Infant Formula Supplemented with Human Milk Oligosaccharides (2'Fucosyllactose and Lacto-N-neotetraose) Shifts Stool Microbiota and Metabolic Signatures Closer to that of Breastfed Infants. The FASEB Journal. 2016; 30, 275.7.

153. Marriage BJ, Buck RH, Goehring KC, Oliver JS, Williams JA. Infants Fed a Lower Calorie Formula With 2'FL Show Growth and 2'FL Uptake Like Breast-Fed Infants. $J$ Pediatr Gastroenterol Nutr. 2015; 61, 649-658. 
154. Bode L, Jantscher-Krenn E. Structure-function relationships of human milk oligosaccharides. Adv Nutr. 2012; 3, 383S-391S.

155. Hunt KM, Foster JA, Forney LJ, et al. Characterization of the diversity and temporal stability of bacterial communities in human milk. PLoS One. 2011; 6, e21313.

156. Cabrera-Rubio R, Collado MC, Laitinen $\mathrm{K}$, et al. The human milk microbiome changes over lactation and is shaped by maternal weight and mode of delivery. Am $J$ Clin Nutr. 2012; 96, 544-551.

157. Murphy K, Curley D, O'Callaghan TF, et al. The Composition of Human Milk and Infant Faecal Microbiota Over the First Three Months of Life: A Pilot Study. Sci Rep. 2017; 7, 40597.

158. Bergmann H, Rodriguez JM, Salminen S, Szajewska H. Probiotics in human milk and probiotic supplementation in infant nutrition: a workshop report. Br J Nutr. 2014; 112, 1119-1128.

159. Boix-Amoros A, Collado MC, Mira A. Relationship between Milk Microbiota, Bacterial Load, Macronutrients, and Human Cells during Lactation. Front Microbiol. 2016; 7, 492.

160. Pannaraj PS, Li F, Cerini C, et al. Association between breast milk bacterial communities and establishment and development of the infant gut microbiome. JAMA Pediatrics. 2017; 171, 647-654.

161. FAO/WHO, Food and Agriculture Organization of the United Nations/World Health Organization. Health and Nutritional Properties of Probiotics in Food including Powder Milk with Live Lactic Acid Bacteria. Available at: http://isappscience.org/wpcontent/uploads/2015/12/FAO-WHO-2001-Probiotics-Report.pdf. 2001, Accessed May 2017.

162. Hill C, Guarner F, Reid G, et al. Expert consensus document: The International Scientific Association for Probiotics and Prebiotics consensus statement on the scope and appropriate use of the term probiotic. Nat Rev Gastroenterol Hepatol. 2014; 11, 506-514.

163. Davis EC, Wang M, Donovan SM. The role of early life nutrition in the establishment of gastrointestinal microbial composition and function. Gut Microbes. 20171-29.

164. Szajewska H. What are the indications for using probiotics in children? Arch Dis Child. 2016; 101, 398-403.

165. Hojsak I, Szajewska H, Canani RB, et al. Probiotics for the Prevention of Nosocomial Diarrhea in Children. J Pediatr Gastroenterol Nutr. 2017 [Epub ahead of print].

166. Szajewska H, Canani RB, Guarino A, et al. Probiotics for the Prevention of AntibioticAssociated Diarrhea in Children. J Pediatr Gastroenterol Nutr. 2016; 62, 495-506.

167. Rinne M, Kalliomaki M, Salminen S, Isolauri E. Probiotic intervention in the first months of life: short-term effects on gastrointestinal symptoms and long-term effects on gut microbiota. J Pediatr Gastroenterol Nutr. 2006; 43, 200-205.

168. Maldonado-Lobon JA, Gil-Campos M, Maldonado J, et al. Long-term safety of early consumption of Lactobacillus fermentum CECT5716: A 3-year follow-up of a randomized controlled trial. Pharmacol Res. 2015; 95-96, 12-19.

169. Scalabrin D, Harris C, Johnston WH, Berseth CL. Long-term safety assessment in children who received hydrolyzed protein formulas with Lactobacillus rhamnosus GG: a 5-year follow-up. Eur J Pediatr. 2017; 176, 217-224.

170. Endo A, Prtty A, Kalliomki M, Isolauri E, Salminen S. Long-term monitoring of the human intestinal microbiota from the 2 nd week to 13 years of age. Anaerobe. 2014; 28, 149-156. 
171. Luoto R, Kalliomaki M, Laitinen K, Isolauri E. The impact of perinatal probiotic intervention on the development of overweight and obesity: follow-up study from birth to 10 years. Int J Obes (Lond). 2010; 34, 1531-1537.

172. Hashemi A, Villa CR, Comelli EM. Probiotics in early life: a preventative and treatment approach. Food Funct. 2016; 7, 1752-1768.

173. Petschow BW, Figueroa R, Harris CL, et al. Effects of feeding an infant formula containing Lactobacillus GG on the colonization of the intestine: a dose-response study in healthy infants. J Clin Gastroenterol. 2005; 39, 786-790.

174. Yan F, Liu L, Cao H, et al. Neonatal colonization of mice with LGG promotes intestinal development and decreases susceptibility to colitis in adulthood. Mucosal Immunol. 2017; 10, 117-127.

175. Mugambi MN, Musekiwa A, Lombard M, Young T, Blaauw R. Synbiotics, probiotics or prebiotics in infant formula for full term infants: a systematic review. Nutr J. 2012; $11,81$.

176. Lee le $\mathrm{Y}$, Bharani R, Biswas A, et al. Normal growth of infants receiving an infant formula containing Lactobacillus reuteri, galacto-oligosaccharides, and fructooligosaccharide: a randomized controlled trial. Matern Health Neonatol Perinatol. 2015; $1,9$.

177. Szajewska H, Ruszczynski M, Szymanski H, et al. Effects of infant formula supplemented with prebiotics compared with synbiotics on growth up to the age of 12 mo: a randomized controlled trial. Pediatr Res. 2017; 81, 752-758.

178. Perez-Munoz ME, Arrieta MC, Ramer-Tait AE, Walter J. A critical assessment of the "sterile womb" and "in utero colonization" hypotheses: implications for research on the pioneer infant microbiome. Microbiome. 2017; 5, 48.

179. Mueller NT, Bakacs E, Combellick J, Grigoryan Z, Dominguez-Bello MG. The infant microbiome development: mom matters. Trends Mol Med. 2015; 21, 109-117.

180. Francino MP. Early development of the gut microbiota and immune health. Pathogens. 2014; 3, 769-790.

181. Funkhouser LJ, Bordenstein SR. Mom knows best: the universality of maternal microbial transmission. PLoS Biol. 2013; 11, e1001631.

182. Vyas U, Ranganathan N. Probiotics, prebiotics, and synbiotics: gut and beyond. Gastroenterol Res Pract. 2012; 2012, 872716.

183. van den Nieuwboer M, Claassen E, Morelli L, Guarner F, Brummer RJ. Probiotic and synbiotic safety in infants under two years of age. Beneficial Microbes. 2014; 5, 4560.

184. White RA, Bjornholt JV, Baird DD, et al. Novel developmental analyses identify longitudinal patterns of early gut microbiota that affect infant growth. PLoS Comput Biol. 2013; 9, e1003042.

185. O'Sullivan A, Farver M, Smilowitz JT. The Influence of Early Infant-Feeding Practices on the Intestinal Microbiome and Body Composition in Infants. Nutr Metab Insights. 2015; 8, 1-9.

186. Scheepers LE, Penders J, Mbakwa CA, et al. The intestinal microbiota composition and weight development in children: the KOALA Birth Cohort Study. Int J Obes (Lond). 2015; 39, 16-25.

187. Dogra S, Sakwinska O, Soh SE, et al. Dynamics of infant gut microbiota are influenced by delivery mode and gestational duration and are associated with subsequent adiposity. MBio. 2015; 6, e02419-14. 
188. Cox LM, Yamanishi S, Sohn J, et al. Altering the intestinal microbiota during a critical developmental window has lasting metabolic consequences. Cell. 2014; 158, 705-721.

189. Yatsunenko T, Rey FE, Manary MJ, et al. Human gut microbiome viewed across age and geography. Nature. 2012; 486, 222-227.

190. Palmer C, Bik EM, DiGiulio DB, Relman DA, Brown PO. Development of the human infant intestinal microbiota. PLoS Biol. 2007; 5, e177.

191. Rodriguez JM, Murphy K, Stanton C, et al. The composition of the gut microbiota throughout life, with an emphasis on early life. Microb Ecol Health Dis. 2015; 26, 26050.

192. Marques TM, Wall R, Ross RP, et al. Programming infant gut microbiota: influence of dietary and environmental factors. Curr Opin Biotechnol. 2010; 21, 149-156.

193. Azad MB, Konya T, Maughan H, et al. Gut microbiota of healthy Canadian infants: profiles by mode of delivery and infant diet at 4 months. CMAJ. 2013; 185, 385-394.

194. Bezirtzoglou E, Tsiotsias A, Welling GW. Microbiota profile in feces of breast- and formula-fed newborns by using fluorescence in situ hybridization (FISH). Anaerobe. $2011 ; 17,478-482$.

195. Fallani M, Young D, Scott J, et al. Intestinal microbiota of 6-week-old infants across Europe: geographic influence beyond delivery mode, breast-feeding, and antibiotics. $J$ Pediatr Gastroenterol Nutr. 2010; 51, 77-84.

196. Klaassens ES, Boesten RJ, Haarman M, et al. Mixed-species genomic microarray analysis of fecal samples reveals differential transcriptional responses of bifidobacteria in breast- and formula-fed infants. Appl Environ Microbiol. 2009; 75, 2668-2676.

197. Thompson AL, Monteagudo-Mera A, Cadenas MB, Lampl ML, Azcarate-Peril MA. Milk- and solid-feeding practices and daycare attendance are associated with differences in bacterial diversity, predominant communities, and metabolic and immune function of the infant gut microbiome. Front Cell Infect Microbiol. 2015; 5, 3.

198. Eggesbo M, Moen B, Peddada S, et al. Development of gut microbiota in infants not exposed to medical interventions. APMIS. 2011; 119, 17-35.

199. Ding T, Schloss PD. Dynamics and associations of microbial community types across the human body. Nature. 2014; 509, 357-360.

200. Luoto R, Kalliomaki M, Laitinen K, et al. Initial dietary and microbiological environments deviate in normal-weight compared to overweight children at 10 years of age. J Pediatr Gastroenterol Nutr. 2011; 52, 90-95.

201. Vael C, Verhulst SL, Nelen V, Goossens H, Desager KN. Intestinal microflora and body mass index during the first three years of life: an observational study. Gut Pathog. 2011; 3, 8.

202. Kalliomaki M, Collado MC, Salminen S, Isolauri E. Early differences in fecal microbiota composition in children may predict overweight. Am J Clin Nutr. 2008; 87, 534-538.

203. Pham VT, Lacroix C, Braegger CP, Chassard C. Early colonization of functional groups of microbes in the infant gut. Environ Microbiol. 2016; 18, 2246-2258.

204. Backhed F, Roswall J, Peng Y, et al. Dynamics and Stabilization of the Human Gut Microbiome during the First Year of Life. Cell Host Microbe. 2015; 17, 690-703.

205. Bokulich NA, Chung J, Battaglia T, et al. Antibiotics, birth mode, and diet shape microbiome maturation during early life. Sci Transl Med. 2016; 8, 343ra382. 
206. Martin FP, Moco S, Montoliu I, et al. Impact of breast-feeding and high- and lowprotein formula on the metabolism and growth of infants from overweight and obese mothers. Pediatr Res. 2014; 75, 535-543.

207. Hascoet JM, Hubert C, Rochat F, et al. Effect of formula composition on the development of infant gut microbiota. J Pediatr Gastroenterol Nutr. 2011; 52, 756762.

208. Oda H, Wakabayashi H, Yamauchi K, Abe F. Lactoferrin and bifidobacteria. Biometals. 2014; 27, 915-922.

209. Mastromarino P, Capobianco D, Campagna G, et al. Correlation between lactoferrin and beneficial microbiota in breast milk and infant's feces. Biometals. 2014; 27, 10771086.

210. Yaron S, Shachar D, Abramas L, et al. Effect of high beta-palmitate content in infant formula on the intestinal microbiota of term infants. J Pediatr Gastroenterol Nutr. 2013; 56, 376-381.

211. Nejrup RG, Licht TR, Hellgren LI. Fatty acid composition and phospholipid types used in infant formulas modifies the establishment of human gut bacteria in germ-free mice. Sci Rep. 2017; 7, 3975.

212. Le Huerou-Luron I, Bouzerzour K, Ferret-Bernard S, et al. A mixture of milk and vegetable lipids in infant formula changes gut digestion, mucosal immunity and microbiota composition in neonatal piglets. Eur J Nutr. 2016 [Epub ahead of print].

213. Donovan SM, Wang M, Li M, et al. Host-microbe interactions in the neonatal intestine: role of human milk oligosaccharides. Adv Nutr. 2012; 3, 450S-455S.

214. Prentice P, Vervoort J, Dingess K, et al. Human milk short chain fatty acid composition is associated with infancy adiposity outcomes [abstract]. In: Abstracts of the 49th Annual Meeting of the European Society for Paediatric Gastroenterology, Hepatology and Nutrition; 2016 May 25-28; Athens. ESPGHAN; 2016. Abstract nr 634.

215. Layden BT, Angueira AR, Brodsky M, Durai V, Lowe WL, Jr. Short chain fatty acids and their receptors: new metabolic targets. Transl Res. 2013; 161, 131-140.

216. Kaji I, Karaki S, Kuwahara A. Short-chain fatty acid receptor and its contribution to glucagon-like peptide-1 release. Digestion. 2014; 89, 31-36.

217. Zadeh-Tahmasebi M, Duca FA, Rasmussen BA, et al. Activation of Short and Long Chain Fatty Acid Sensing Machinery in the Ileum Lowers Glucose Production in Vivo. Journal of Biological Chemistry. 2016; 291, 8816-8824.

218. Chambers ES, Viardot A, Psichas A, et al. Effects of targeted delivery of propionate to the human colon on appetite regulation, body weight maintenance and adiposity in overweight adults. Gut. 2015; 64, 1744-1754.

219. Tolhurst G, Heffron H, Lam YS, et al. Short-chain fatty acids stimulate glucagon-like peptide-1 secretion via the G-protein-coupled receptor FFAR2. Diabetes. 2012; 61, 364-371.

220. Psichas A, Sleeth ML, Murphy KG, et al. The short chain fatty acid propionate stimulates GLP-1 and PYY secretion via free fatty acid receptor 2 in rodents. Int $J$ Obes (Lond). 2015; 39, 424-429.

221. Everard A, Cani PD. Gut microbiota and GLP-1. Reviews in Endocrine and Metabolic Disorders. 2014; 15, 189-196.

222. Baggio LL, Drucker DJ. Biology of incretins: GLP-1 and GIP. Gastroenterology. 2007; 132, 2131-2157.

223. Tian L, Jin T. The incretin hormone GLP-1 and mechanisms underlying its secretion. Journal of Diabetes. 2016; 8, 753-765. 
224. Wu T, Rayner CK, Horowitz M. Incretins. Handb Exp Pharmacol. 2016; 233, $137-$ 171.

225. Delzenne NM, Neyrinck AM, Backhed F, Cani PD. Targeting gut microbiota in obesity: effects of prebiotics and probiotics. Nat Rev Endocrinol. 2011; 7, 639-646.

226. Alvaro A, Sola R, Rosales R, et al. Gene expression analysis of a human enterocyte cell line reveals downregulation of cholesterol biosynthesis in response to short-chain fatty acids. IUBMB Life. 2008; 60, 757-764.

227. Gao Z, Yin J, Zhang J, et al. Butyrate improves insulin sensitivity and increases energy expenditure in mice. Diabetes. 2009; 58, 1509-1517.

228. Zaibi MS, Stocker CJ, O'Dowd J, et al. Roles of GPR41 and GPR43 in leptin secretory responses of murine adipocytes to short chain fatty acids. FEBS Lett. 2010; 584, 23812386.

229. Xiong Y, Miyamoto N, Shibata K, et al. Short-chain fatty acids stimulate leptin production in adipocytes through the G protein-coupled receptor GPR41. Proc Natl Acad Sci U S A. 2004; 101, 1045-1050.

230. Ye J, Wu W, Li Y, Li L. Influences of the Gut Microbiota on DNA Methylation and Histone Modification. Digestive Diseases and Sciences. 2017; 62, 1155-1164.

231. Bhat MI, Kapila R. Dietary metabolites derived from gut microbiota: critical modulators of epigenetic changes in mammals. Nutrition Reviews. 2017; 75, 374-389.

232. Majnik AV, Lane RH. The relationship between early-life environment, the epigenome and the microbiota. Epigenomics. 2015; 7, 1173-1184.

233. Woo V, Alenghat T. Host-microbiota interactions: epigenomic regulation. Curr Opin Immunol. 2017; 44, 52-60.

234. Aoyama M, Kotani J, Usami M. Butyrate and propionate induced activated or nonactivated neutrophil apoptosis via HDAC inhibitor activity but without activating GPR-41/GPR-43 pathways. Nutrition. 2010; 26, 653-661.

235. Davie JR. Inhibition of histone deacetylase activity by butyrate. J Nutr. 2003; 133, 2485S-2493S.

236. Sanderson IR. Short chain fatty acid regulation of signaling genes expressed by the intestinal epithelium. J Nutr. 2004; 134, 2450S-2454S.

237. Remely M, Aumueller E, Merold C, et al. Effects of short chain fatty acid producing bacteria on epigenetic regulation of FFAR3 in type 2 diabetes and obesity. Gene. 2014; 537, 85-92.

238. Krautkramer KA, Kreznar JH, Romano KA, et al. Diet-Microbiota Interactions Mediate Global Epigenetic Programming in Multiple Host Tissues. Molecular Cell. 2016; 64, 982-992.

239. Kumar H, Lund R, Laiho A, et al. Gut microbiota as an epigenetic regulator: pilot study based on whole-genome methylation analysis. MBio. 2014; 5, e 02113-14.

240. Mischke M, Plosch T. More than just a gut instinct-the potential interplay between a baby's nutrition, its gut microbiome, and the epigenome. Am J Physiol Regul Integr Comp Physiol. 2013; 304, R1065-1069.

241. Brands B, Demmelmair H, Koletzko B. How growth due to infant nutrition influences obesity and later disease risk. Acta Paediatr. 2014; 103, 578-585.

242. Perfilyev A, Dahlman I, Gillberg L, et al. Impact of polyunsaturated and saturated fat overfeeding on the DNA-methylation pattern in human adipose tissue: a randomized controlled trial. Am J Clin Nutr. 2017; 105, 991-1000.

243. Singh N, Shirdel EA, Waldron L, et al. The murine caecal microRNA signature depends on the presence of the endogenous microbiota. Int J Biol Sci. 2012; 8, 171 186. 
244. Dalmasso G, Nguyen HT, Yan Y, et al. Microbiota modulate host gene expression via microRNAs. PLoS One. 2011; 6, e19293.

245. Weber JA, Baxter DH, Zhang S, et al. The microRNA spectrum in 12 body fluids. Clin Chem. 2010; 56, 1733-1741.

246. Alsaweed M, Hartmann PE, Geddes DT, Kakulas F. MicroRNAs in Breastmilk and the Lactating Breast: Potential Immunoprotectors and Developmental Regulators for the Infant and the Mother. Int J Environ Res Public Health. 2015; 12, 13981-14020.

247. Golan-Gerstl R, Elbaum Shiff Y, Moshayoff V, et al. Characterization and biological function of milk-derived miRNAs. Mol Nutr Food Res. 2017 [Epub ahead of print].

248. Izumi H, Kosaka N, Shimizu T, et al. Bovine milk contains microRNA and messenger RNA that are stable under degradative conditions. J Dairy Sci. 2012; 95, 4831-4841.

249. Roura E, Koopmans SJ, Lalles JP, et al. Critical review evaluating the pig as a model for human nutritional physiology. Nutr Res Rev. 2016; 29, 60-90. 


\section{Figure legends}

Fig. 1. Short- and plausible long-term effects of neonatal feeding

BF, breastfed infants; CHD, coronary heart disease; FA, fatty acid; HMOs, human milk oligosaccharides; IF, infant formula; IGF-1, insulin-like growth factor-1; IR, insulin resistance; LDL, low density lipoprotein; MFGM, milk fat globule membrane; TD2, type-2 diabetes; TG, triglycerides

\section{Fig. 2. Long-term metabolic health: the potential pathways involving gut microbiota}

GLP-1, glucagon-like peptide-1; HMOs, human milk oligosaccharides; IGF-1, insulin-like growth factor-1; miRNAs, non-coding microRNAs; PYY, peptide YY; SCFAs, short-chain fatty acids 


\section{Figure 1}

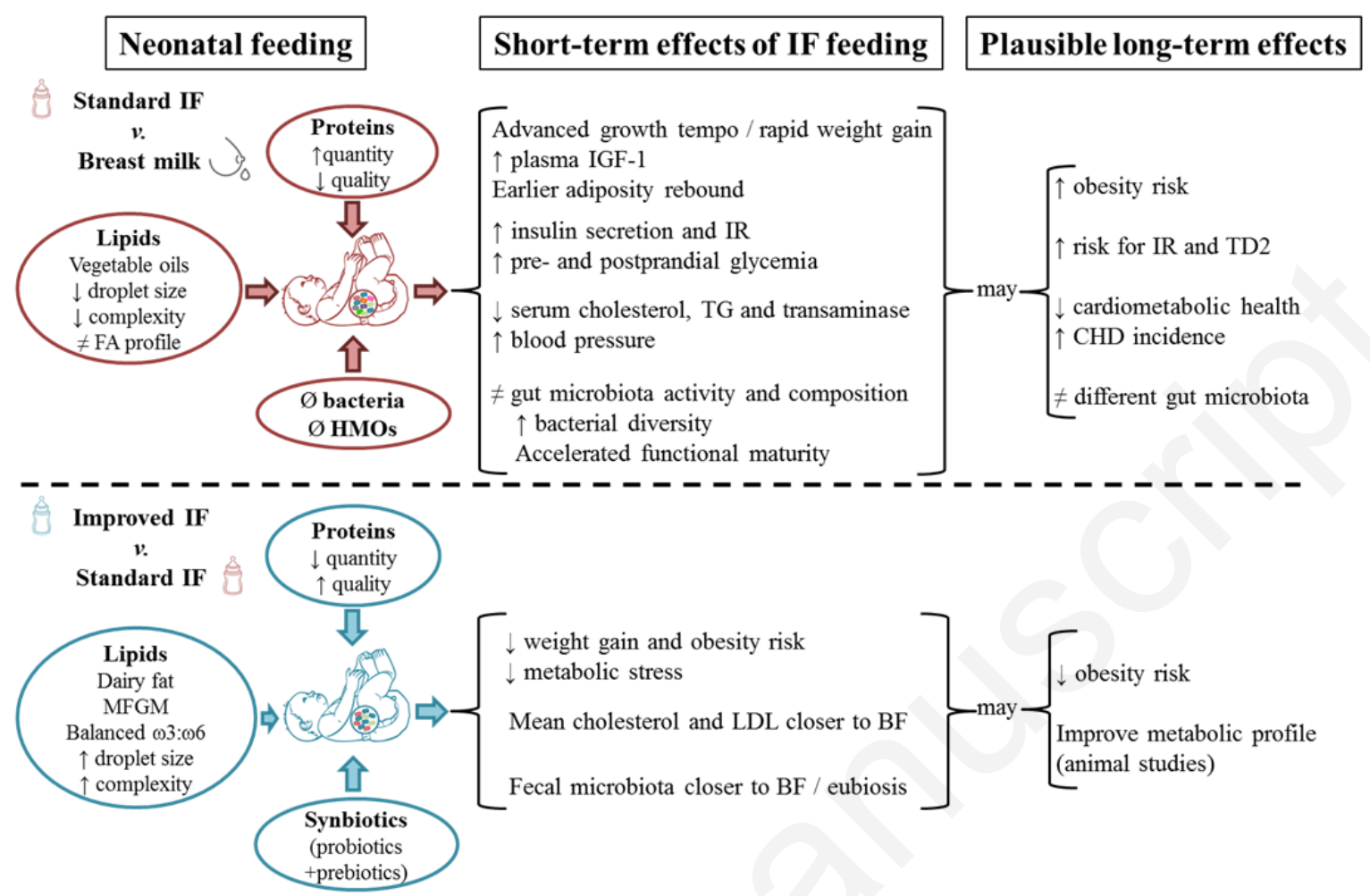

Fig. 1. Short- and plausible long-term effects of neonatal feeding

IF, infant formula; $v$, versus; FA, fatty acid; HMOs, human milk oligosaccharides; IGF-1, insulin-like growth factor-1; IR, insulin resistance;

TG, triglycerides; TD2, type-2 diabetes; CHD, coronary heart disease; MFGM, milk fat globule membrane; LDL, low density lipoprotein; BF, breastfed infants 


\section{Figure 2}

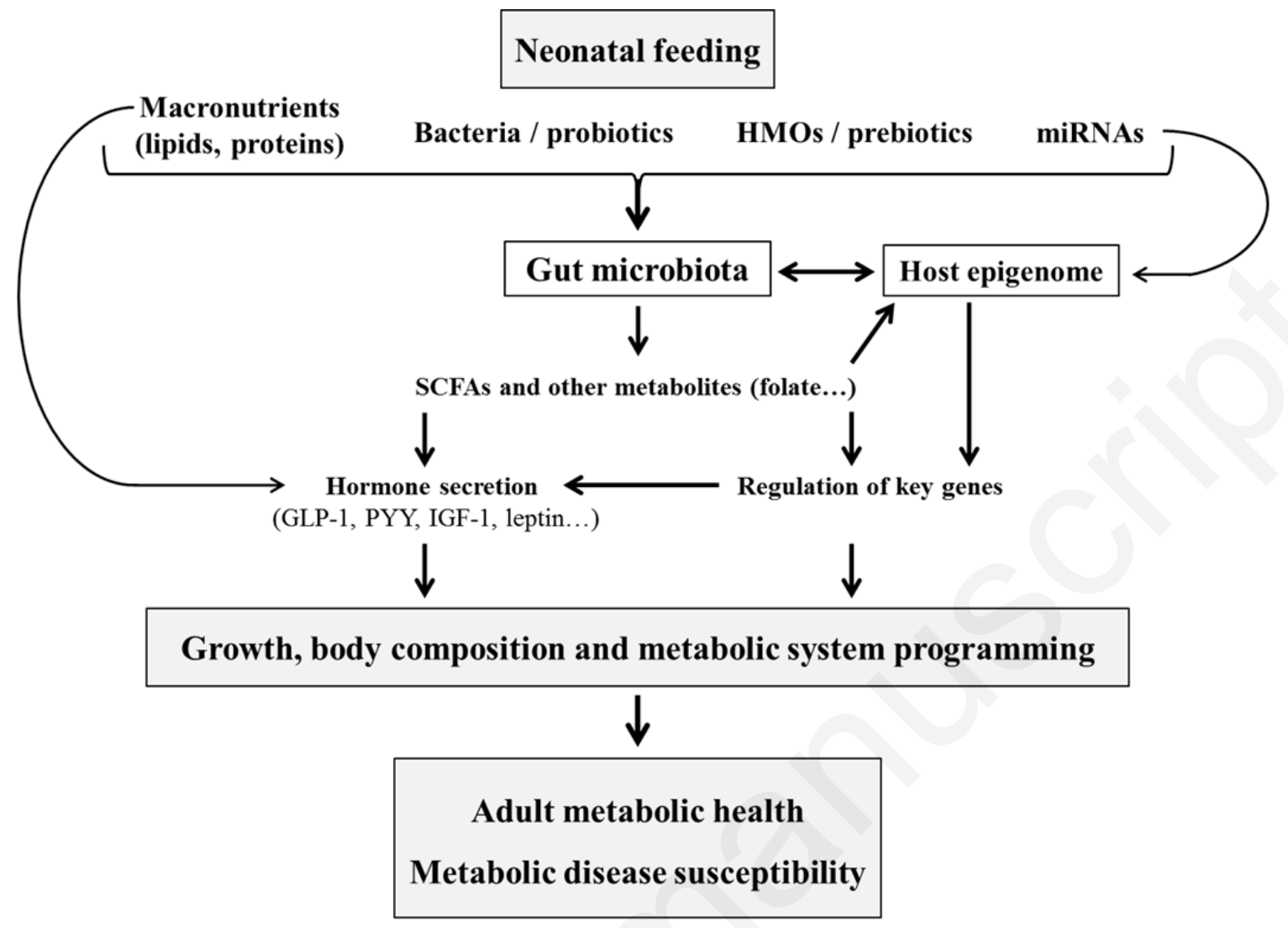

Fig. 2. Long-term metabolic health: the potential pathways involving gut microbiota

HMOs, human milk oligosaccharides; miRNAs, non-coding microRNAs; SCFAs, short-chain fatty acids; GLP-1, glucagon-like peptide-1; PYY, peptide YY; IGF-1, insulin-like growth factor-1 